OPEN ACCESS

Edited by:

Jesus Tejero,

University of Pittsburgh, United States

Reviewed by:

Tomoyoshi Tamura,

Brigham and Women's Hospital,

United States

Motoaki Sano,

Keio University School of

Medicine, Japan

Yoji Hakamata

Nippon Veterinary and Life Science

University, Japan

*Correspondence:

Youzhen Wei

wei-youzhen@163.com

orcid.org/0000-0002-5634-6073

Jing Qiao

qiaojing@tongji.edu.cn

Jianjun Zhou

zhouij_2000@aliyun.com

Specialty section:

This article was submitted to

Redox Physiology,

a section of the journal

Frontiers in Physiology

Received: 06 October 2021 Accepted: 22 November 2021 Published: 20 December 2021

Citation:

Tian $Y$, Zhang $Y$, Wang $Y$, Chen $Y$,

Fan W, Zhou J, Qiao J and Wei $Y$ (2021) Hydrogen, a Novel Therapeutic Molecule, Regulates Oxidative Stress,

Inflammation, and Apoptosis.

Front. Physiol. 12:789507.

doi: 10.3389/fphys.2021.789507

\section{Hydrogen, a Novel Therapeutic Molecule, Regulates Oxidative Stress, Inflammation, and Apoptosis}

\author{
Yan Tian ${ }^{1}$, Yafang Zhang ${ }^{2}$, Yu Wang ${ }^{1,3}$, Yunxi Chen ${ }^{1}$, Weiping Fan ${ }^{3}$, Jianjun Zhou ${ }^{1 *}$, \\ Jing Qiao ${ }^{4 *}$ and Youzhen Wei ${ }^{1 *}$
}

${ }^{1}$ Research Center for Translational Medicine, Tongji University Affiliated East Hospital, Shanghai, China, ${ }^{2}$ Department of Pediatrics, Taian City Central Hospital, Taian, China, ${ }^{3}$ Department of Microbiology and Immunology, Shanxi Medical University, Taiyuan, China, ${ }^{4}$ Department of Pediatrics, Tongji University Affiliated East Hospital, Shanghai, China

Molecular hydrogen $\left(\mathrm{H}_{2}\right)$ is a colorless and odorless gas. Studies have shown that $\mathrm{H}_{2}$ inhalation has the therapeutic effects in many animal studies and clinical trials, and its application is recommended in the novel coronavirus pneumonia treatment guidelines in China recently. $\mathrm{H}_{2}$ has a relatively small molecular mass, which helps it quickly spread and penetrate cell membranes to exert a wide range of biological effects. It may play a role in the treatment and prevention of a variety of acute and chronic inflammatory diseases, such as acute pancreatitis, sepsis, respiratory disease, ischemia reperfusion injury diseases, autoimmunity diseases, etc.. $\mathrm{H}_{2}$ is primarily administered via inhalation, drinking $\mathrm{H}_{2}$-rich water, or injection of $\mathrm{H}_{2}$ saline. It may participate in the anti-inflammatory and antioxidant activity (mitochondrial energy metabolism), immune system regulation, and cell death (apoptosis, autophagy, and pyroptosis) through annihilating excess reactive oxygen species production and modulating nuclear transcription factor. However, the underlying mechanism of $\mathrm{H}_{2}$ has not yet been fully revealed. Owing to its safety and potential efficacy, $\mathrm{H}_{2}$ has a promising potential for clinical use against many diseases. This review will demonstrate the role of $\mathrm{H}_{2}$ in antioxidative, anti-inflammatory, and antiapoptotic effects and its underlying mechanism, particularly in coronavirus disease-2019 (COVID-19), providing strategies for the medical application of $\mathrm{H}_{2}$ for various diseases.

Keywords: molecular hydrogen $\left(\mathrm{H}_{2}\right)$, reactive oxygen species, antioxidant, anti-inflammatory, antiapoptotic

\section{INTRODUCTION}

Molecular hydrogen $\left(\mathrm{H}_{2}\right)$ is the lightest and most abundant element in the earth's atmosphere. It was considered as a new type of natural antioxidant with low capacity to react with most biomolecules, which has potential therapeutic benefits. The first application of $\mathrm{H}_{2}$ for humans is hydreliox, a breathing gas mixture of $\mathrm{H}_{2}$, helium, and oxygen $\left(\mathrm{O}_{2}\right)$, which is used to prevent decompression sickness and nitrogen narcosis during very deep technical diving (Lanphier, 1972). Therapeutic applications of $\mathrm{H}_{2}$ were first demonstrated in 1975, showing that hyperbaric $\mathrm{H}_{2}$ caused marked regression of tumors in mice with skin squamous carcinoma (Dole et al., 1975). In 2007, a Japanese scholar discovered that inhalation of low concentration $\mathrm{H}_{2}$ could significantly inhibit cerebral ischemia-reperfusion (I/R) injury and stroke in rats by buffering oxidative stress (Ohsawa et al., 2007). Since then, the biomedical effects, mainly antioxidative, anti-inflammatory, 
and antiapoptotic effects of $\mathrm{H}_{2}$ have been explored with many cellular, animal, and clinical studies. Despite many inaccuracies, selective free radical and inflammation scavenging ability are still the widely accepted mechanism of $\mathrm{H}_{2}$. Our previous study also revealed that preinhalation of $\mathrm{H}_{2}$ could protect caeruleininduced acute pancreatitis in mice by inhibiting inflammation and oxidative stress in the early stage (Yin et al., 2021). Clinical trials have demonstrated that $\mathrm{H}_{2}$ treatment was safe and effective in patients with asthma and chronic obstructive pulmonary disease (COPD) (Wang S. T. et al., 2020; Zheng Z. G. et al., 2021). Furthermore, therapeutic effects in patients with oxidative stress caused by cardiac arrest and inflammation caused by sports have also been shown (Ostojic et al., 2014; Tamura et al., 2020). Most recently and remarkably, to confront coronavirus disease-2019 (COVID-19) pandemic caused by severe acute respiratory syndrome coronavirus 2 (SARS-CoV-2), starting from the Chinese Clinical Guidance (7th edition) for COVID-19 Pneumonia Diagnosis and Treatment issued by China National Health Commission, the inhalation of $\mathrm{O}_{2}$ mixed with $\mathrm{H}_{2}$ gas $\left(33.3 \% \mathrm{O}_{2}\right.$ and $\left.66.6 \% \mathrm{H}_{2}\right)$ has been recommended due to the significant role of $\mathrm{H}_{2}$ in ameliorating lung function decline, emphysema, and inflammation in acute or chronic pulmonary disease (Guan et al., 2020a). The therapeutic effects of $\mathrm{H}_{2}$ will be highlighted.

Thus, this review will discusses the new application $\mathrm{H}_{2}$ and for COVID-19, apart from the scavenger properties of $\mathrm{H}_{2}$ against excess reactive oxygen species (ROS) and abnormal inflammation.

\section{MOLECULAR HYDROGEN}

\section{Introduction of Hydrogen Physiology}

Molecular hydrogen is a kind of colorless, odorless, and minimal molecule in nature. $\mathrm{H}_{2}$ gas is flammable and will burn in air at a very wide range of concentrations between 4 and $75 \%$ by volume. Actually, it could quickly diffuse through the alveoli into the blood and circulate throughout the body during breathing; then, given the small relative molecular weight and lack of polarity, $\mathrm{H}_{2}$ can quickly penetrate the cell membrane and disperse to the cytoplasm, nucleus, and other organelles to play the biological role. Moreover, $\mathrm{H}_{2}$ passes through the blood-brain barrier although most antioxidant compounds cannot. As a kind of mild gas, no cytotoxicity has been reported on the body due to $\mathrm{H}_{2}$ so far. $\mathrm{H}_{2}$ also has no direct effect on physiology, such as body temperature, blood pressure, $\mathrm{pH}$, or $\mathrm{pO}_{2}$ (Zhou et al., 2019). However, it may play an anti-inflammatory and antioxidative role by directly affecting mitochondrial electron transport and neutralizing oxidative stress to alleviate mitochondrial damage, or by balancing intracellular environmental homeostasis and affecting the transcription of key regulatory proteins of inflammation (Ostojic, 2015). $\mathrm{H}_{2}$ gas or $\mathrm{H}_{2}$-dissolved solution concentration is measurable by gas chromatography. $\mathrm{H}_{2}$ concentration also can be specifically detected by an $\mathrm{H}_{2}$ electrode. When gas chromatography was used to detect $\mathrm{H}_{2}$ content, it was found that there was almost no $\mathrm{H}_{2}$ in the arterial blood, venous blood, heart, liver, and other tissues in normal rats (Liu et al., 2014; Chen O. et al., 2017). In mammals, the mammalian cells cannot produce $\mathrm{H}_{2}$ because of the deficiency of hydrogenases. However, in human, $\mathrm{H}_{2}$-producing bacteria through anaerobic metabolism in the gut produces $\mathrm{H}_{2}$ at about 50 to $1,000 \mathrm{mg}$ /day by decomposing lactulose (Hylemon et al., 2018), and very small amounts of $\mathrm{H}_{2}$ can quickly escape into the blood circulation and exhale out of the body (8-10 ppm) (Shin, 2014), which can be used to monitor health. Furthermore, lactulose is a safe and tolerable source of $\mathrm{H}_{2}$ production (Ito et al., 2012). The inhalation of $\mathrm{H}_{2}$ actually increases dissolved $\mathrm{H}_{2}$ in arterial blood in a $\mathrm{H}_{2}$ concentrationdependent manner, and the $\mathrm{H}_{2}$ levels in venous blood were lower than in arterial blood (Ohsawa et al., 2007).

\section{Routes of Hydrogen Administration}

Conventionally, the strategies of $\mathrm{H}_{2}$ administration in animal model and human researches are classified into three types, namely inhalation of $\mathrm{H}_{2}$ gas, drinking $\mathrm{H}_{2}$-dissolved water, and injection of $\mathrm{H}_{2}$-dissolved saline. In recent years, nanomaterial delivery systems have also been developed. However, the effects from all delivery strategies are dependent on the solubility of $\mathrm{H}_{2}$ in water, saline, or blood, as show in Table 1.

Inhalation of $\mathrm{H}_{2}$ gas is the most straightforward therapeutic method and has been widely used since the first report. Inhalation of $\mathrm{H}_{2}$ ensures the retention time and dose in the body. Inhaled $\mathrm{H}_{2}$ diffuses through the alveoli into the plasma and is transported through the blood to the body. A clinical examination demonstrated that exposure to $2.4 \% \mathrm{H}_{2}$ gas for $72 \mathrm{~h}$ does not affect any physiological parameters, suggesting $\mathrm{H}_{2}$ may not have adverse effects (Cole et al., 2021). However, the chemical property of $\mathrm{H}_{2}$ is that it burns with $\mathrm{O}_{2}$ to form water. It may be explosive and dangerous when the concentration in the air is higher than $4 \%$, but a research reported that $\mathrm{H}_{2}$ does not explode if it is $<10 \%$ when mixed with air or $\mathrm{O}_{2}$ (Kurokawa et al., 2019). In addition, reports indicated that the antioxidant effect of $\mathrm{H}_{2}$ was dose-dependent, and the concentration of $\mathrm{H}_{2}$ in blood and tissues was dependent on the time and concentration of inhalation (Fukuda et al., 2007). In recent years, the administration of a mixture of $\mathrm{H}_{2}$ and $\mathrm{O}_{2}$ gases $\left(66 \% \mathrm{H}_{2} ; 33 \%\right.$ $\mathrm{O}_{2}$ ), obtained by the electrolysis of water, for research and clinical investigation has become more and more common ( $\mathrm{Li} \mathrm{H}$. et al., 2017; Chen et al., 2020). The application of high concentrations of $\mathrm{H}_{2}$ gas may result in more effective outcomes. The generator represents a safe and convenient alternative to high-pressure gas cylinders and requires no replenishment of supplies.

Drinking water containing $\mathrm{H}_{2}$ may be more beneficial since it is a portable, safe, and easily administered way to ingest. $\mathrm{H}_{2}$ can be dissolved in water up to $0.8 \mathrm{mM}(1.6 \mathrm{mg} / \mathrm{L})$ under atmospheric pressure at room temperature without any change of $\mathrm{pH}$. However, the low solubility of $\mathrm{H}_{2}$ in water may not be able to guarantee enough $\mathrm{H}_{2}$ concentration in certain local damage models, resulting in its poor bioavailability. Propitiously, drinking $\mathrm{H}_{2}$ water can be administered frequently to overcome a short half-life. It was estimated that $\sim 41 \%$ of ingested $\mathrm{H}_{2}$ via $\mathrm{H}_{2}$-rich water was retained in the body (Shimouchi et al., 2012). However, the concentration of $\mathrm{H}_{2}$ in the brain of rats may be too low when using traditional $\mathrm{H}_{2}$ sensors after drinking 
TABLE 1 | $\mathrm{H}_{2}$ intake route and typical management schemes.

\begin{tabular}{|c|c|c|c|c|c|c|c|}
\hline Intake route & Advantages & Disadvantages & Subjects & Action time & Action effects & Intake protocol & References \\
\hline \multirow[t]{6}{*}{$\begin{array}{l}\text { Inhalation of } \\
\mathrm{H}_{2} \text { gas }\end{array}$} & $\begin{array}{l}\text { Ensures the } \\
\text { intake time and } \\
\text { dose }\end{array}$ & $\begin{array}{l}\text { May be } \\
\text { explosive when } \\
\text { the } \\
\text { concentration is } \\
\text { higher than } 4 \%\end{array}$ & Rats & $120 \mathrm{~min}$ & $\begin{array}{l}\text { Inhibits cerebral l/R injury; } \\
\text { antioxidant }\end{array}$ & 1,2 or $4 \% \mathrm{H}_{2}$ & $\begin{array}{l}\text { Ohsawa et al. } \\
\text { (2007) }\end{array}$ \\
\hline & & & Human & 7 days & Improves COPD symptoms & $66.6 \% \mathrm{H}_{2} 6-8 \mathrm{~h} / \mathrm{d}$ & $\begin{array}{l}\text { Zheng Z. G. et al. } \\
(2021)\end{array}$ \\
\hline & & & Rats & 4 months & $\begin{array}{l}\text { Improves COPD symptoms; } \\
\text { anti-inflammation }\end{array}$ & $\begin{array}{l}41.6,22 \text { or } 2 \% \mathrm{H}_{2} \\
\text { once a day for } 2 \mathrm{~h}\end{array}$ & Liu et al. (2017) \\
\hline & & & Mice & 7 days & $\begin{array}{l}\text { Improves asthma } \\
\text { symptoms; } \\
\text { anti-inflammation }\end{array}$ & $\begin{array}{l}42 \% \mathrm{H}_{2} \text { twice a } \\
\text { day, } 2 \mathrm{~h} \text { /day }\end{array}$ & Huang et al. (2019) \\
\hline & & & Human & $\begin{array}{l}\text { Every day until } \\
\text { discharge }\end{array}$ & Improves COVID-19 severity & $\begin{array}{l}33.3 \% \mathrm{O}_{2} \text { and } \\
66.6 \% \mathrm{H}_{2}\end{array}$ & $\begin{array}{l}\text { Guan et al. } \\
(2020 b)\end{array}$ \\
\hline & & & Rats & $12 \mathrm{~h}$ & $\begin{array}{l}\text { Alleviates acute pancreatitis; } \\
\text { anti-inflammation }\end{array}$ & $2 \% \mathrm{H}_{2}$ & Zhou et al. (2016) \\
\hline \multirow{6}{*}{$\begin{array}{l}\text { Drinking } \\
\mathrm{H}_{2} \text {-dissolved } \\
\text { water }\end{array}$} & $\begin{array}{l}\text { Portable and } \\
\text { safe }\end{array}$ & $\begin{array}{l}\text { Limited intake } \\
\text { dose }\end{array}$ & Human & 2 weeks & $\begin{array}{l}\text { Alleviates sports-related soft } \\
\text { tissue injuries }\end{array}$ & $\begin{array}{l}\mathrm{H}_{2} \text {-rich tablets, } 2 \\
\text { g/day }\end{array}$ & $\begin{array}{l}\text { Ostojic et al. } \\
(2014)\end{array}$ \\
\hline & & & $\begin{array}{l}\text { Guinea } \\
\text { Pigs }\end{array}$ & 10 days & $\begin{array}{l}\text { Ameliorates allergic rhinitis; } \\
\text { immunoregulation }\end{array}$ & $\begin{array}{l}20 \mu \mathrm{L} / \text { day } \\
\text { introduced into } \\
\text { nasal passage; } 0.6 \\
\mathrm{mmol} / \mathrm{L}\end{array}$ & Xu et al. (2018) \\
\hline & & & Human & 4 weeks & $\begin{array}{l}\text { Reduces inflammation and } \\
\text { apoptosis of peripheral } \\
\text { blood cells }\end{array}$ & $\begin{array}{l}0.753 \mathrm{mg} / \mathrm{L} \\
1,500 \mathrm{ml} / \text { day }\end{array}$ & Sim et al. (2020) \\
\hline & & & Mice & 10 days & $\begin{array}{l}\text { Alleviates EAE symptoms; } \\
\text { anti-inflammation }\end{array}$ & $\begin{array}{l}0.36 \text { or } 0.89 \mathrm{mM} \\
\text { twice a day }\end{array}$ & Zhao et al. (2016) \\
\hline & & & Human & 8 weeks & $\begin{array}{l}\text { Improves parapsoriasis en } \\
\text { plaques }\end{array}$ & $\begin{array}{l}\mathrm{H}_{2} \text { water bathing } \\
\text { twice a week, } \\
\text { 10-15 min ever } \\
\text { time }\end{array}$ & Zhu et al. (2018) \\
\hline & & & Rats & 60 or $90 \mathrm{~min}$ & $\begin{array}{l}\text { Relieve retina injury; } \\
\text { antiapoptotic }\end{array}$ & $\begin{array}{l}\text { Saturated } \mathrm{H}_{2} \text { eye } \\
\text { drops }\end{array}$ & $\begin{array}{l}\text { Oharazawa et al. } \\
(2010)\end{array}$ \\
\hline \multirow[t]{3}{*}{$\begin{array}{l}\text { Injection of } \\
\mathrm{H}_{2} \text {-dissolved } \\
\text { saline }\end{array}$} & $\begin{array}{l}\text { Ensures the } \\
\text { dose and direct } \\
\text { application to } \\
\text { the affected area }\end{array}$ & $\begin{array}{l}\text { Invasive and has } \\
\text { the risk of } \\
\text { cross-infection }\end{array}$ & Rats & $24 \mathrm{~h}$ & $\begin{array}{l}\text { Alleviates inflammation } \\
\text { and apoptosis in myocardial } \\
\text { I/R injury }\end{array}$ & $\begin{array}{l}0.6 \mathrm{mmol} / \mathrm{L}, 10 \\
\mathrm{ml} / \mathrm{kg}\end{array}$ & Yao L. et al. (2019) \\
\hline & & & Mice & $12 \mathrm{~h}$ & $\begin{array}{l}\text { Attenuates } \\
\text { sepsis-associated } \\
\text { encephalopathy; } \\
\text { anti-inflammation }\end{array}$ & $\begin{array}{l}0.6 \mathrm{mmol} / \mathrm{L}, 5 \\
\mathrm{~mL} / \mathrm{kg}\end{array}$ & Xie et al. (2020) \\
\hline & & & Rats & $2 \mathrm{~h}$ & Attenuates acute lung injury & 2.5 or $10 \mathrm{~mL} / \mathrm{kg}$ & Zou et al. (2019) \\
\hline $\begin{array}{l}\text { Nanoparticle } \\
\text { delivery }\end{array}$ & $\begin{array}{l}\text { Safe and higher } \\
\mathrm{H}_{2} \text { content per } \\
\text { unit volume }\end{array}$ & Expensive & Rats & 3 or $24 h$ & $\begin{array}{l}\text { Attenuates myocardial I/R } \\
\text { injury; anti-inflammation and } \\
\text { antioxidant }\end{array}$ & $\begin{array}{l}4 \times 10^{9} \text { or } 2 \times 10^{10} \\
\text { bubbles }\end{array}$ & He et al. (2017) \\
\hline
\end{tabular}

$\mathrm{H}_{2}$ water (Liu et al., 2014). Thus, it is essential to achieve high payload delivery of $\mathrm{H}_{2}$ at specific locations to improve the efficacy of $\mathrm{H}_{2}$ intervention. In recent years, He et al. (2017) designed a microbubbles (MBs) delivery and monitoring system for $\mathrm{H}_{2}$ application, which is a delivery vehicle with which $\mathrm{H}_{2}$ gas can be loaded onto the MB shell and can be transported via blood circulation. $\mathrm{H}_{2}$ content per unit volume of solution was higher when using $\mathrm{MBs}$ than using $\mathrm{H}_{2}$-saturated saline, implying that $\mathrm{H}_{2}$-MBs could be a better method for prevention of myocardial $\mathrm{I} / \mathrm{R}$ injury in a rat model.
Due to the hydrogen's ability to diffuse through the membrane into the cells, $\mathrm{H}_{2}$ bathing research has evolved in therapeutic applications. $\mathrm{H}_{2}$ water bathing showed positive effects in the treatment of skin diseases (Zhu et al., 2018; Asada et al., 2019). Expanding the application for $\mathrm{H}_{2}$ is preservation of graft organs. Excised grafts were submersed in saturated $\mathrm{H}_{2}$-rich water during cold preservation which attenuated cold I/R injury of grafts (Noda et al., 2013), and alleviated chronic graft-vs. -host disease by inhibiting excessive inflammation and oxidative stress (Qian et al., 2021). Moreover, retinal I/R injury was shown in animal 
models by transient elevation of intraocular pressure and a mechanistic increase in ROS, and this injury was reversed by the continuous delivery of $\mathrm{H}_{2}$ saturated eye drops, especially in apoptosis (Oharazawa et al., 2010).

Molecular hydrogen saline injection is a method that can rapidly supply a large amount of $\mathrm{H}_{2}$ into the body and allows $\mathrm{H}_{2}$ for the direct application to the affected area. However, this method is invasive, difficult for patients to accept, and has the potential risk of crossinfection. In addition, it could be very dangerous if $\mathrm{H}_{2}$ is injected directly into the skin or vein. In a study using a rat model, $\mathrm{H}_{2}$ was administered orally, injected intraperitoneally or intravenously, or inhaled in its $\mathrm{H}_{2}$-water, $\mathrm{H}_{2}$-saline, or $\mathrm{H}_{2}$ gas forms, respectively. After measuring the concentration of $\mathrm{H}_{2}$ by high-quality sensor gas chromatography, $\mathrm{H}_{2}$ was present in different concentrations in different tissues (Liu et al., 2014). Thus, $\mathrm{H}_{2}$ can reach to most organs or blood independently by the three methods.

However, different administration methods may have different effects. A pharmacokinetics research of a single inhalation of $\mathrm{H}_{2}$ gas in pigs showed that $\mathrm{H}_{2}$ concentration in the carotid artery peaked immediately after breath holding, and it dropped to $1 / 40$ of the peak value 3 min later. Peak $\mathrm{H}_{2}$ concentration in venous blood was much lower than that in arterial blood, which indicated that $\mathrm{H}_{2}$ is not simply diffused, but diffuses while being carried by the blood stream (Sano et al., 2020). Hydrogen peaks in inhalation and oral delivery at almost the same time, but the sustaining time of drinking $\mathrm{H}_{2}$ water is longer (Sobue et al., 2015). For protein expression, drinking $\mathrm{H}_{2}$ water could more significantly downregulate the expression of NF- $\kappa B$ in rats liver tissue than $\mathrm{H}_{2}$ inhalation, and the combined effect was even better (Sobue et al., 2015). The concentrations of $\mathrm{H}_{2}$ reached a maximum at $5 \mathrm{~min}$ after the oral or intraperitoneal $\mathrm{H}_{2}$ administration, while intravenous treatment used only $1 \mathrm{~min}$. The decline of the $\mathrm{H}_{2}$ concentrations in the blood and tissues observed after reaching the highest level at 5 min was more rapid following intraperitoneal administration than oral administration. The inhalation of $\mathrm{H}_{2}$ gas resulted in slower elevation of the $\mathrm{H}_{2}$ concentration than that achieved with intraperitoneal, intravenous, or oral administration. However, the elevated $\mathrm{H}_{2}$ by inhaling was maintained for at least $60 \mathrm{~min}$ (Liu et al., 2014). The fact that inhalation takes a longer time for tissue $\mathrm{H}_{2}$ concentration to saturate than ingestion of $\mathrm{H}_{2}$ water is counterintuitive, which is because of using especial hermetic tubes filled with pure air to prevent the leakage of $\mathrm{H}_{2}$ from the sampling tissue during processing and the application of highquality sensor gas chromatography in this work. In addition, different methods of $\mathrm{H}_{2}$ inhalation give different results, such as masks or nasal tubes. Thus, different administration routes of $\mathrm{H}_{2}$ need to be considered according to the needs of the user to guarantee the best acceptable benefits.

\section{BIOLOGICAL EFFECTS OF HYDROGEN}

\section{Antioxidant Effect} Neutralization of ROS

The disequilibrium between ROS and the antioxidant system causes oxidative stress which is considered as a common initial step for many pathological processes (Burton and Jauniaux, 2011). These ROS include superoxide anion $\left(\mathrm{O}_{2} \bullet-\right)$, hydroxyl $(\bullet \mathrm{OH})$, peroxyl $\left(\mathrm{RO}_{2} \bullet\right)$, alkoxyl $(\mathrm{RO} \bullet)$ radicals, and nitric oxide (NO•), and they primarily come from mitochondrial respiration, $\mathrm{NADH} / \mathrm{NADPH}$ oxidase, or xanthine oxidoreductase (Dan Dunn et al., 2015). When cell damage occurs, oxidative phosphorylation and electron transport in mitochondria are obstructed, and electrons are leaked to produce excess ROS. On the one hand, the overproduction of ROS causes damage of cell membrane or organelle membrane. Then the lipids are detached from the membrane and further peroxide to generate arachidonic acid and leukotrienes, which contribute to inflammatory pain. Furthermore, ROS produced by neutrophils and macrophages could attack pathogens, which may damage the structure of mitochondria and nucleus of normal cells and subsequently lead to the initiation of apoptosis (Wang et al., 2017). There is no known enzyme specifically to deal with $\bullet \mathrm{OH}$, since the $\bullet \mathrm{OH}$ nonselectively reacts instantaneously with the nearest nucleophilic biomolecules. $\mathrm{H}_{2}$ is a new type of reductant that can penetrate the cell membrane and neutralize particles that damage the body, $\bullet \mathrm{OH}$ and $\mathrm{ONOO}^{-}$in cellular structure, and almost no effects of $\mathrm{O}_{2}^{-}$and $\mathrm{H}_{2} \mathrm{O}_{2}$ which maintains physiological function and internal environment stability (Ohta, 2014). The direct scavenging of the hydroxyl radical according to the chemical reaction of $\mathrm{H}_{2}+\bullet \mathrm{OH} \rightarrow \mathrm{H}_{2} \mathrm{O}+\mathrm{H} \bullet$ followed by $\mathrm{H} \bullet+$ $\mathrm{O}_{2}^{-} \rightarrow \mathrm{HO}_{2}^{-}$was considered as a potential mode of action (LeBaron et al., 2019). As early as 2001, Gharib et al. (2001) found that $\mathrm{H}_{2}$ could increase superoxide dismutase (SOD) activity and reduce lipid peroxide malondialdehyde (MDA) level in schistosomiasis-associated liver inflammation model. In 2007, Ohsawa et al. (2007) described its protective benefit against reperfusion oxidative injury in vitro and in vivo. They demonstrated the protective potential of $\mathrm{H}_{2}$ against I/ $\mathrm{R}$ injury, where $\mathrm{H}_{2}$ reduced oxidative stress and scavenged $\cdot \mathrm{OH}$ and $\mathrm{ONOO}^{-}$, acting as an electron donor for ROS molecules, but the direct ROS scavenging effect of $\mathrm{H}_{2}$ is only confirmed in the acellular experiment. Similarly, after administration with $1.3 \%$ $\mathrm{H}_{2}$ gas inhalation for 2 weeks in vasculitis mice, the tissue damage was decreased as a result of reduction of $\cdot \mathrm{OH}$ and $\mathrm{ONOO}^{-}$(Kiyoi et al., 2020). By regulating their concentration, they also prevent the production of hydroxyl radicals as they can be converted to - $\mathrm{OH}$ radicals via the Haber-Weiss and Fenton reaction in the presence of catalytically active metals such as $\mathrm{Fe}^{2+}$ and $\mathrm{Cu}^{+}$ (Huang, 2016).

Furthermore, the biological and antioxidant effects of $\mathrm{H}_{2}$ remain even after $\mathrm{H}_{2}$ has been cleared from the body, especially at a low concentration (Dixon et al., 2013), which suggests that the mechanism may have more to do with antioxidant signal modulation than direct free radical scavenging. Nuclear factor erythroid-2 related factor 2 (Nrf2) shifting into the nucleus could lead to the regulation of gene expression involved in defense systems against oxidative stress (Tonelli et al., 2018). Studies have shown that $\mathrm{H}_{2}$-rich saline gavage can improve the symptoms of experimental autoimmune encephalomyelitis (EAE) in mice by activating the Nrf2-ARE signaling pathway (Liu et al., 2019). In addition, $\mathrm{H}_{2}$ significantly reduces intracellular ROS by upregulating Nrf2 transcription to promote the expression of 
SOD and glutathione (GSH) and downregulating the expression of NADPH oxidase ( $\mathrm{Su}$ et al., 2019; Zhao et al., 2019). $\mathrm{H}_{2}$ could protect cells against cell death by blocking the abnormal oxidation of phospholipids, reducing the increase in the cell membrane permeability, and thus blocking lipid peroxidation may be another important mechanism of $\mathrm{H}_{2}$ antioxidation (Iuchi et al., 2019). Unexpectedly, recent notable studies have suggested that excessive antioxidants increased mortality rates of cancer and cardiovascular diseases (Poljsak et al., 2013; Singh et al., 2018). An ideal antioxidant is expected to mitigate excess oxidative stress, but not to disturb redox homeostasis. $\mathrm{H}_{2}$ might be the ideal antioxidant via the rapid diffussion into cells by blood circulation.

\section{Regulation of Mitochondria}

In addition to focusing on $\mathrm{H}_{2}$ neutralizing oxidative stress, the processes upstream of the dysfunction of electron transport chain were focused, which is the first step during mitochondrial oxidative stress. Mitochondria are generally termed the powerhouses of the cell as they produce the $90 \%$ of energy in the form of ATP. This process relies on oxidative phosphorylation and accompanies the generation of ROS by forward and reverse electron transfer (Annesley and Fisher, 2019). $\mathrm{H}_{2}$ improves mitochondrial dysfunction by preventing the uncontrolled electron leakage from the electron transport chain and is predicted to have the potential ability to regenerate the dysfunction of the cells.

ATP-sensitive $\mathrm{K}+$ channel $\left(\mathrm{mK}_{\mathrm{ATP}}\right)$, which is an important energy regulation participant, is located on the mitochondria. For acute myocardial infarction, $\mathrm{H}_{2}$ gas could activate $\mathrm{mK}_{\mathrm{ATP}}$ and regulate mitochondrial membrane potential to equilibrize the level of myocardial NAD+ (the precursor of ATP synthesis) and the production of mitochondrial ATP, thus alleviating myocardial I/R injury (Yoshida et al., 2012).

Coenzyme $\mathrm{Q}(\mathrm{CoQ})$ is a key component of the mitochondrial electron transfer chain. The dominant form is CoQ10 in human, while it is CoQ9 in rats. CoQ accepts electrons from Complex I and Complex II and transfers to Complex III, which contributes to the generation of NAD+, the precursor to ATP production and the proton motive force for ATP production (Gutierrez-Mariscal et al., 2020). After $\mathrm{H}_{2}$ application, $\mathrm{CoQ9}$ concentrations in plasma and myocardium tissue of rats were significantly increased. In addition, increased CoQ9 improves ATP production via mitochondrial oxidative phosphorylation (Gvozdjakova et al., 2020). $\mathrm{H}_{2}$ gas has been suggested to enhance the clinical efficacy of nivolumab by increasing CoQ10 of mitochondria to restore exhausted CD8 $+\mathrm{T}$ cells (Akagi and Baba, 2020). Therefore, we believe that $\mathrm{H}_{2}$ can protect against cell damage by improving mitochondrial function. Improvement of mitochondrial dysfunction is also expected to improve the disordered signal transduction that affects cellular death process, such as Bax and caspase activities (Liu et al., 2016).

Mitophagy plays an important role in maintaining mitochondria homeostasis by eliminating damaged or dysfunctional mitochondria. Fun 14 domain-containing protein 1 (Fundc1) is one of mitophagy receptors localized on the outer membrane of the mitochondrion, which can maintain mitochondrial ATP balance by regulating the mitophagy and interacting with LC3 II. Administration with $2 \% \mathrm{H}_{2}$ for $3 \mathrm{~h}$ promoted Fundc1-induced mitophagy and protected mice from the sepsis-induced liver injury (Yan et al., 2019). In addition, $\mathrm{H}_{2}$ exerts neuroprotective effect on oxygen/glucose deprivation neuronal damage in rats, and the increasing expression of mitophagy-related factors, PINK1 and Parkin, indicated that $\mathrm{H}_{2}$ is beneficial for ATP generation by promoting mitochondrial autophagy (Wu X. et al., 2018). Animal studies of sepsis have identified the mitochondrial dysfunction may reduce the cellular energy level, resulting in sepsis-related multiple organ failure. For example, in myocardial tissues, $\mathrm{H}_{2}$ treatment scavenged ROS by upregulating the heme oxygenase-1 (HO-1, known as heat shock protein 32) to protect sepsis-related multiple organ injury in HO-1/Nrf2 dependent manner (Zhang et al., 2020).

Mitochondrial damage induced by excessive ROS is an important cause of many neurodegenerative diseases. Antioxidant effects of $\mathrm{H}_{2}$ intervention on Parkinson's disease or Alzheimer's disease animal models have been shown in previous studies (Wang et al., 2011; Hirayama et al., 2018). However, a randomized double-blind placebo-controlled trial showed that patients with Parkinson's disease who inhaled $6.5 \% \mathrm{H}_{2}$ gas at $2 \mathrm{~L} / \mathrm{min}$ for 16 weeks, twice a day for $1 \mathrm{~h}$ did not show any beneficial effects even though $\mathrm{H}_{2}$ gas was safe (Yoritaka et al., 2021). We believe that this may be related to $\mathrm{H}_{2}$ concentration and treatment duration time. Since this clinical trial has only a small number of participants, further study is needed. In conclusion, we assume that $\mathrm{H}_{2}$ could equilibrate mitochondrial electron flow, which can explain its ability to scavenge ROS and improve mitochondrial energy metabolism.

\section{Anti-inflammatory Effect}

Inflammation is considered as an adaptive response of the body caused by infection of foreign pathogens or tissue damage, which can cause the aggregation of local neutrophils, monocytes, and other immune cells and release inflammatory cytokines. This process is manifested as lymphocytes and mononuclear phagocytes migrating from veins to the site of injury tissue and getting activated and differentiated into macrophages, in which phagocytes are the main source of growth factors and cytokines (Eming et al., 2017). In addition, excess intracellular ROS can activate inflammatory transcription factors, such as nuclear factor $\kappa \mathrm{B}$ (NF- $\kappa \mathrm{B}), \mathrm{p} 53$, hypoxia-inducible factor- $1 \alpha$ (HIF-1 $\alpha$ ), matrix metalloproteinases, peroxisome proliferatoractivated receptor- $\gamma$, and nitrosyl radicals, and initiate apoptosis (Mittal et al., 2014; Rimessi et al., 2016; Forrester et al., 2018). Therefore, in the whole pathological process of oxidative stress, inflammation, cell damage, and apoptosis accompany each other and are mutually influenced.

At the early stage of inflammation, $\mathrm{H}_{2}$ can reduce the infiltration of neutrophils and macrophages by downregulating the expression of intercellular adhesion molecules and chemokines (Chen et al., 2018), such as early proinflammatory cytokines IL- $1 \beta$ and TNF- $\alpha$, subsequently decreasing the inflammatory cytokines such as IL-6 and IFN- $\gamma$ (Zhao et al., 2013). Wang et al. (2015) found that $\mathrm{H}_{2}$-rich saline inhibited 
the activation of crucial inflammatory signaling pathway NF$\kappa B$ and reduced serum IL- $1 \beta$, IL- 6 , and TNF- $\alpha$ levels, thus alleviating the airway inflammatory response caused by a burn in rats. In addition, $\mathrm{H}_{2}$ can significantly reduce the expression of NF-кB in liver injury (Tan et al., 2014), hematencephalon (Zhuang et al., 2019), and skeletal muscle injury caused by acute sports (Nogueira et al., 2020), suggesting that molecular hydrogen can affect the inflammatory process by regulating nuclear transcription factors and downstream proinflammatory cytokines. Besides, for the treatment of diseases of inflammation dysfunction, the balance between anti-inflammation and proinflammation should be emphasized. $\mathrm{H}_{2}$ also displays an anti-inflammatory effect in $\mathrm{I} / \mathrm{R}$ cerebral injury or allergic rhinitis animal model by upregulating regulatory $\mathrm{T}$ cells (Tregs), which exerts the immunosuppressive function and inhibits the expression of NF-kB (Li et al., 2016; Xu et al., 2018).

Heme oxygenase-1 belongs to the heat-shock protein family, which is a rate-limiting microsomal enzyme involved in heme catabolism. The product, biliverdin, is rapidly reduced to bilirubin, a potent endogenous antioxidant. It could suppress the expression of IL- $1 \beta$ and NF- $\mathrm{B}$, limiting septic injury (Fujioka et al., 2017). Studies have demonstrated that $\mathrm{H}_{2}$ administration increased the HO- 1 expression and the number of anti-inflammatory cytokines, IL-10, in human umbilical vein endothelial cells stimulated by LPS and lung tissue of lunginjured mice (Chen et al., 2015). Similarly, we found that preinhalation of $\mathrm{H}_{2}$ could prevent acute pancreatitis in mice effectively by enhancing the expression of Hsp60 protein, a heat stress protein, that stimulated synthesis by high temperature to protect itself, in the early stage (Yin et al., 2021). Therefore, we believe that $\mathrm{H}_{2}$ can mobilize the body's defense response to play a prominent role in anti-inflammation.

\section{Regulating Cell Death Apoptosis}

Apoptosis is a type of programmed cell death characterized by cell atrophy, apoptotic body formation, and chromatin condensation. The result is clearing cells from the body and minimizing the damage to surrounding tissues, which plays a pivotal role in normal cell turnover and tissue homeostasis. Apoptosis can be induced by both intrinsic and extrinsic signals. The extrinsic apoptotic pathway is initiated by the death receptors on the cell surface, which interact with the tumor necrosis factor receptor and Fas, resulting in the activation of the downstream caspase- 8 and subsequent apoptosis. The intrinsic apoptotic pathway is closely related to the antiapoptotic B-cell lymphoma 2 (Bcl-2) and proapoptotic Bax proteins. Both apoptotic pathways converge at a common end-point, leading to caspase-3 activation and DNA fragmentation (Obeng, 2021). $\mathrm{H}_{2}$ may exert antiapoptotic effect through scavenging ROS or regulation of gene transcription, which may regulate endogenous apoptosis.

An in vitro experiment showed that $\mathrm{H}_{2}$-rich medium significantly inhibited ROS formation, maintained cell viability, and inhibited caspase- 3 and caspase- 9 in intestinal epithelial cells. Moreover, the inordinate expression of Bax and Bcl-2 was also redressed by $\mathrm{H}_{2}$ (Qiu et al., 2020). This effect of $\mathrm{H}_{2}$-rich water may be achieved through inhibiting the translocation of the apoptotic markers, caspase- 3 and Bax, to the mitochondria (Zhang Q. et al., 2018). $\mathrm{H}_{2}$-rich water also could play an antiapoptotic role through upregulating the expression of $\mathrm{Bcl}-2$, an important antiapoptotic factor (Mo et al., 2019). Furthermore, $\mathrm{H}_{2}$ can activate the MAPK/HO-1 pathway to inhibit neuronal apoptosis and alleviate ischemic brain injury in neonatal mice (Wang et al., 2020) or protect type II alveolar epithelial cells from hyperoxia-induced apoptosis by activating the PI3K/Akt signaling pathway (Wu D. et al., 2018). Interestingly, $\mathrm{H}_{2}$ may have different regulatory effects on tumors, that is, it promoted cell apoptosis and inhibited the growth, migration, and invasion of lung cancer and esophageal cancer cells in vitro by upregulating the expression of cleaved caspase-3 ( $\mathrm{Li} \mathrm{Q}$. et al., 2017; Meng et al., 2020), indicating promising application of $\mathrm{H}_{2}$ in tumor therapy. Thus, we suggest that $\mathrm{H}_{2}$ may play a multiple role, protecting normal cells from damage and inhibiting the proliferation of cancer cells.

\section{Autophagy}

Autophagy can maintain the energy balance by degrading macromolecular substances, but excessive autophagy will aggravate the inflammation and damage of tissues and organs, such as in sepsis. Autophagy-related proteins play a pivotal role in autophagy detection, including light chain 3 protein (LC3) and Beclin-1. Zhang et al. (2017) illustrated that $\mathrm{H}_{2}$ alleviated isoproterenol-induced cardiomyocytes injury through inhibiting autophagy. $\mathrm{H}_{2}$ saturated water significantly reduced the expression of autophagy-related proteins LC3 and Beclin-1 in LPS-induced lung injury, suggesting that $\mathrm{H}_{2}$ protected tissues from excessive autophagy (Zhang et al., 2015). However, $\mathrm{H}_{2}$ could alleviate LPS-induced neuroinflammation by reducing the expression of mTOR in glial cells, increasing the LC3 II/LC3 I ratio, and promoting autophagy (Zhuang et al., 2020). This may be related to different severity of LPS-induced inflammation models. Fundc1, a mitophagy receptor localized at the membrane of the mitochondrion, can maintain mitochondrial ATP balance by regulating mitophagy. Administration with $2 \% \mathrm{H}_{2}$ for $3 \mathrm{~h}$ promoted Fundc1-induced mitophagy and protected mice from the sepsis-induced liver injury (Yan et al., 2019). In addition, studies have shown that the LC3 II/LC3 I ratio and Beclin-1 expression of the damaged cardiomyocytes increased under the regulation of $\mathrm{H}_{2}$-rich water, indicating that $\mathrm{H}_{2}$ was included in the degradation process of injured mitochondria for intracellular homeostasis (Yao L. et al., 2019). $\mathrm{H}_{2}$ can also activate autophagy by inhibiting stress-related p38 and JNK/MAPK pathways (Guan et al., 2019). Similarly, cell apoptosis and autophagy were significantly enhanced in A549 and H1975 lung cancer cell lines treated with different concentrations of $\mathrm{H}_{2}$ gas (Liu et al., 2020).

In conclusion, we deemed that $\mathrm{H}_{2}$ has a bidirectional regulatory effect on autophagy when autophagy is hyperactivated during inflammation or/and can protect cells and tissues from damage.

\section{Pyrolysis}

Pyrolysis is a programmed death pathway of proinflammatory cells that protects monocytes, macrophages, and other invading 
pathogens (Man et al., 2017). Although pyrolysis is usually beneficial to the host, excessive pyrolysis can lead to sepsis and septic shock. Caspase-1 is a vital factor in the activation of pyrolysis, and cytokines, IL-1 $\beta$ and IL-18, are the main downstream inflammatory factors in the pyrolysis pathway. The protective effects of $\mathrm{H}_{2}$ in septic mice has been demonstrated (Zhai et al., 2015; Xie et al., 2020, 2021). In early subarachnoid hemorrhage brain injury models, $\mathrm{H}_{2}$-rich saline can markedly reduce the expression of caspase-1 and inhibit inflammatory response (Shao et al., 2016). Furthermore, in sepsis-related organ injury models, $\mathrm{H}_{2}$ treatment significantly reduced the expression of caspase- 1 in the damaged organ and the levels of IL- $1 \beta$ and IL18 cytokines (Yan et al., 2019; Xie et al., 2020). We have known that lung inflation with $\mathrm{H}_{2}$ is an effective method to protect donor lungs from I/R injury (Meng C. et al., 2016). Zheng P. et al. (2021) proved that the pyroptosis-related proteins, NLRP3, caspase-1, and the N-terminal of gasdermin D (GSDMD-N), were reduced after lung inflation with $3 \% \mathrm{H}_{2}$, which means $\mathrm{H}_{2}$ alleviated lung $\mathrm{I} / \mathrm{R}$ injury by inhibiting pyroptosis in Wistar rats. However, $\mathrm{H}_{2}$ may play a different regulatory role in tumors. Yang et al. (2020) showed that $\mathrm{H}_{2}$-rich water inhibited the proliferation of endometrial cancer cells by triggering the NLRP3 inflammasome/caspase-1 mediated classical pyroptosis pathway and activated the downstream proinflammatory cytokine IL13. Endotoxin transporter protein HMGB1 is necessary for activation of caspase-11 pyroptosis pathway (Deng et al., 2018), and the negative regulation of $\mathrm{H}_{2}$ on HMGB1 may also play a role in cell pyrolysis (Yu et al., 2019). $\mathrm{H}_{2}$ may exert inhibitory effects on cancer cells through apoptosis, autophagy, and pyrolysis. Although there is no direct evidence to explain the mechanism of $\mathrm{H}_{2}$ in cell pyroptosis, it is conceivable that the regulation of some nuclear factors and inflammatory factors by $\mathrm{H}_{2}$ will interfere with the progress of pyroptosis. The effects of $\mathrm{H}_{2}$ on pyrolysis pathway may inhibit tumor cells or protect normal tissues and

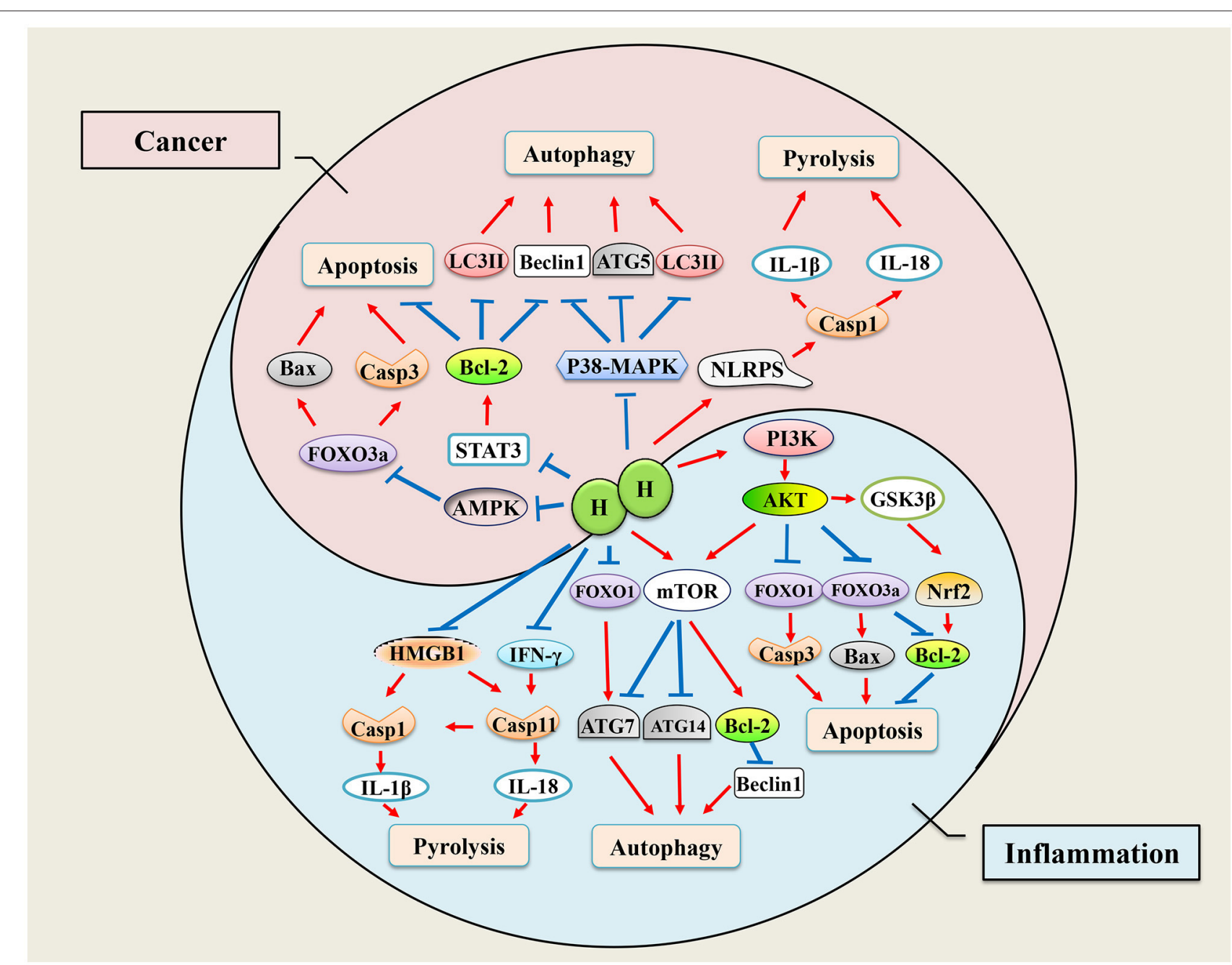

FIGURE 1 | Mechanisms of hydrogen regulates cell death. Hydrogen has bidirectional regulatory effects on apoptosis, autophagy, and pyrolysis. When inflammation occurs, cells initiate apoptosis, autophagy, and pyroptosis to adapt to environmental changes, while hydrogen therapy ameliorates inflammation-induced excessive cell programmed death by regulating transcription of genes. When tumor occurs, hydrogen plays an antitumor role by promoting cell apoptosis, autophagy, and pyrolysis. 
cells from damage, which is similar to that of apoptosis, as shown in Figure 1.

\section{Mechanisms and Perspectives of $\mathrm{H}_{2}$ for COVID-19}

The severe acute bronchitis, pneumonia, and pulmonary fibrosis of coronavirus disease-2019 (COVID-19) caused by severe acute respiratory syndrome coronavirus 2 (SARS-CoV-2) rapidly disseminated across the world in a short span of time, with nearly 185 million confirmed cases and about four million deaths. Most of the cases with COVID-19 manifest as a respiratory illness, starting with a fever and dry cough, followed by shortness of breath with respiratory failure. About $80 \%$ of infected people may recover from the illness without hospitalization, the remainder $(20 \%)$ progress to pneumonia and severe acute respiratory distress syndrome (ARDS), and about $5 \%$ of patients develop severe ARDS (Cascella et al., 2021). Currently, few therapies have been proven to be able to rapidly ameliorate the respiratory symptoms and control the disease progression.

When infection occurs, alveolar macrophages and infiltrated immune cells are activated to release proinflammatory cytokines within alveoli and bronchioles. Alveolar hypoxia further induces inflammatory cascades, leading to the production of excess ROS and activation of hypoxia-inducible factors (HIF-1 $\alpha$ ), and nuclear factor-kappa B (NF-кB) (Dukhinova et al., 2021). Thus, anti-inflammatory and antioxidant therapy are considered essential for severe COVID-19. Inflammatory cytokine storms, caused by an overactive host immune system, can lead to acute inflammatory lung injury and even death (Xu et al., 2020).

Within COVID-19 patients, serum IL-6 and IL-10 levels are positively correlated with disease severity, indicating

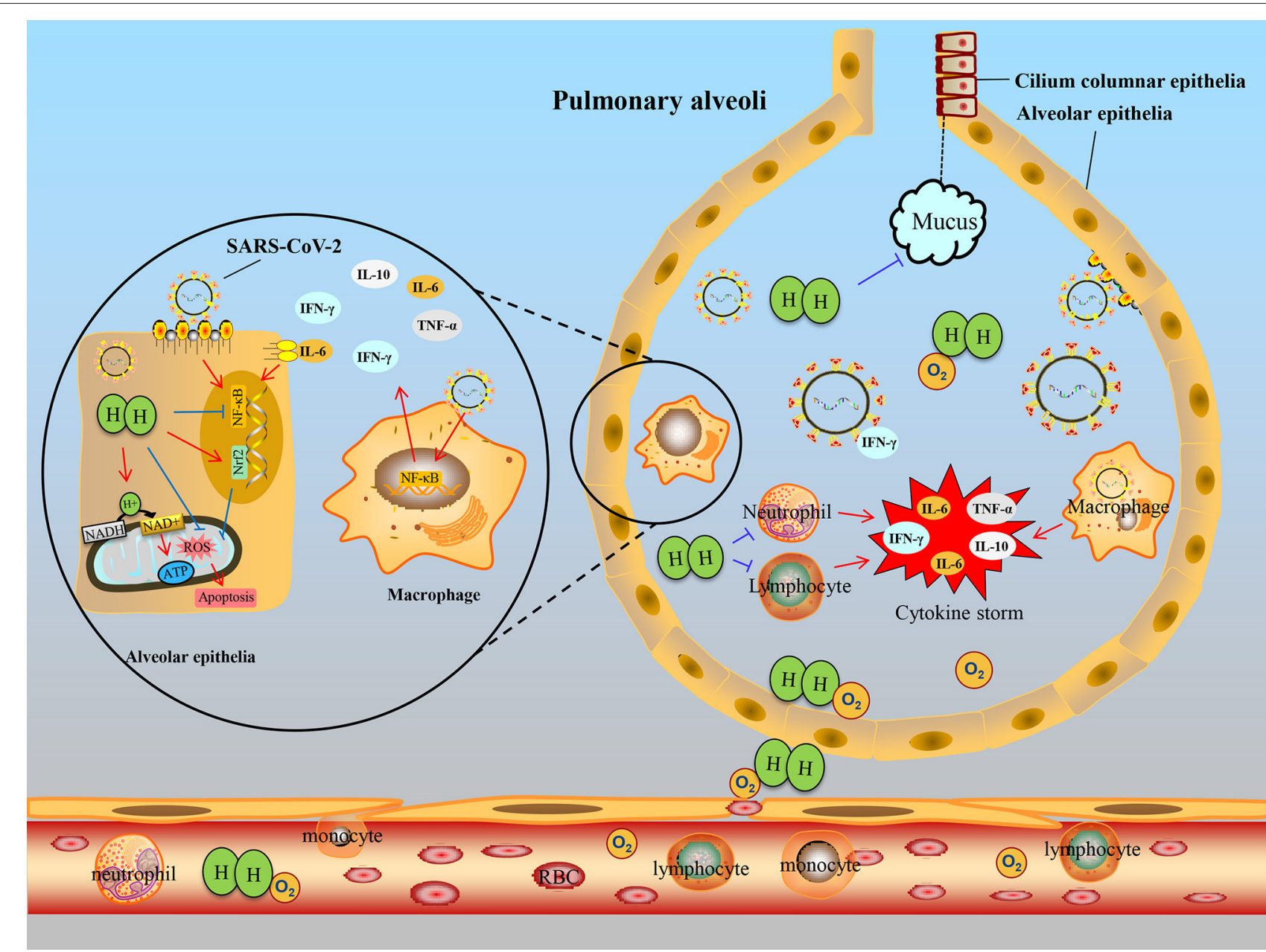

FIGURE 2 | Hypothetical schematic of therapeutic effects of hydrogen for COVID-19. When the SARS-CoV-2 invades the bronchus, the immune defense response is activated, immune cells, such as monocytes and lymphocytes, infiltrate into the alveoli from small vessels, they secrete excessive cytokines IL-6, TNF- $\alpha$, etc., resulting in cytokine storms and alveolar epithelial cell damage. After hydrogen administration, on the one hand, inflammation can be suppressed by inhibiting NF-kB transcription to reduce activated immune cells, especially macrophages. On the other hand, hydrogen entering alveolar epithelial cells buffers oxidative stress or regulates Nrf2 transcription and inhibits apoptosis. Furthermore, hydrogen can improve dyspnea by inhibiting the secretion of mucus in bronchiole and assisting oxygen diffusion. 
inflammatory cytokines might be an indicator for disease prognosis (Han et al., 2020). Inhalation with $2 \% \mathrm{H}_{2}$ significantly reduced the number of inflammatory cells and gene levels of TNF- $\alpha$, IL-6, IL-17, and IL-23 in the bronchoalveolar lavage fluid in animal model (Liu et al., 2017). Wang S. T. et al. (2020) also showed that $45 \mathrm{~min}$ of $\mathrm{H}_{2}$ gas inhalation attenuated airway inflammation in asthma and COPD patients by inhibiting the levels of MCP-1, IL-4, and IL-6. Therefore, the early use of $\mathrm{H}_{2}$ in COVID-19 patients could potentially suppress the cytokine storms and acute lung injury.

Mitochondrial ROS production usually occurs in the early stage of cell injury, which can lead to destruction of the cell membrane of the alveolar epithelial cells and inactivation of surfactant, thus increasing membrane permeability, leading to increased leakage of proteins into the alveoli during lung injury (Alwazeer et al., 2021). Yet despite high-speed oxygen ventilation, inflammation of the respiratory tract and exudation of viscous mucus in bronchioles and alveoli make oxygenation of blood inefficient in severe COVID-19 as $\mathrm{O}_{2}$ cannot easily penetrate mucus plugs. Due to its small molecular weight, $\mathrm{H}_{2}$ could elevate forced vital capacity and decrease total respiratory system resistance (Feng et al., 2019). Moreover, $\mathrm{H}_{2}$ gas may alleviate dyspnea of patients with COPD by inhibiting bronchiole mucus accumulation and goblet cell hyperplasia (Ning et al., 2013). Moreover, ventilation of highly concentrated oxygen in patients with low $\mathrm{SpO} 2$ levels may produce harmful superoxide free radicals, which further paralyzes lung function. Therefore, for COVID-19 patients, inhalation of $\mathrm{H}_{2}$ may offer an effective solution to tackle both hypoxia and oxidative stress, thereby reducing downstream cytokine secretion. Different antioxidants were proposed to prevent lipid peroxidation of lung surfactants such as coenzyme Q10 and vitamin E (Rossi et al., 2018; DiPasquale et al., 2020). Studies have shown that, in animal

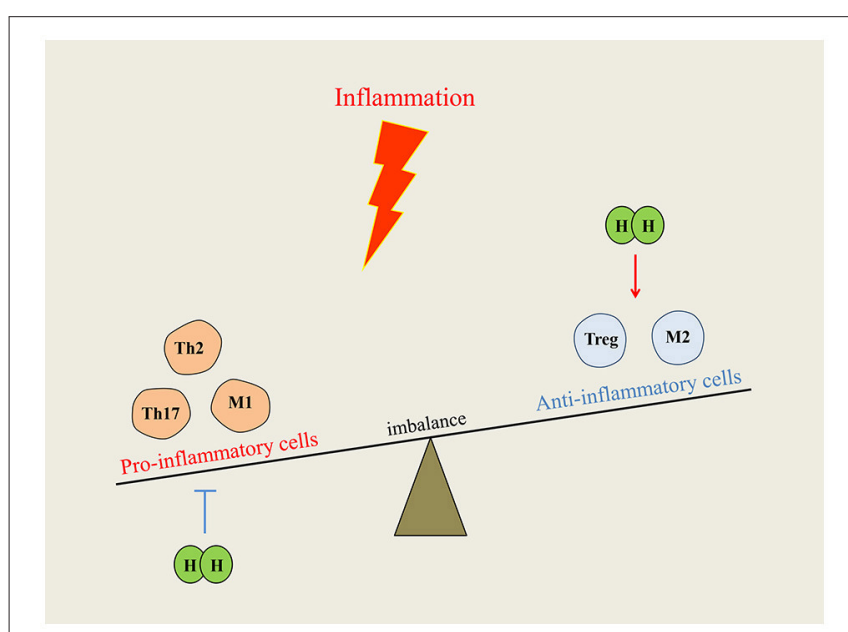

FIGURE 3 | Immunomodulatory function of hydrogen on immune system. When inflammation occurs, the disordered immune cells break the balance of immune homeostasis. Hydrogen intervention could reduce inflammation by downregulating proinflammatory cells or upregulating anti-inflammatory cells, and the imbalance can be redressed. models of airway inflammation, intervention with different concentrations of $\mathrm{H}_{2}$ could reduce oxidative stress markers MDA and improve antioxidant enzymes GSH in serum and lung tissue (Zhang N. et al., 2018; Huang et al., 2019). Importantly, it was reported that $\mathrm{H}_{2}$-rich medium intervention attenuates irradiation-induced human lung epithelial cell line A549 damage by decreasing the production of ROS (Terasaki et al., 2011). There are more studies showing that $\mathrm{H}_{2}$ reduces ROS production in alveolar epithelial cells, attenuates the alveolar epithelial barrier damage, improves alveolar gas exchange, and reduces cell damage (Qiu et al., 2019). Thus, we have reason to believe that $\mathrm{H}_{2}$ can be an effective mitigation for COVID-19 pneumonia by neutralizing oxidative stress. In a recent multicenter clinical trial, we noticed that the researchers used a mixture of $\mathrm{H}_{2}$ and oxygen $\left(\mathrm{O}_{2}\right)$ gas $\left(66 \% \mathrm{H}_{2} ; 33 \% \mathrm{O}_{2}\right)$, generated by electrolyzed water, administered in patients with COVID-19. An improvement in clinical symptoms was seen in a significantly higher percentage of patients in the treatment group, who inhaled a mixture of $\mathrm{H}_{2}$ and $\mathrm{O}_{2}$, than in patients in the control group, who received classic oxygen therapy, although randomization was not applied because of the urgency to deal with the outbreak (Guan et al., 2020b). Similarly, application of $\mathrm{H}_{2}$ improves $\mathrm{O}_{2}$ utilization rate, reduces $\mathrm{O}_{2}$ consumption, and improves exercise endurance as in healthy humans (Alharbi et al., 2021). Inhalation of the mixed gas of $\mathrm{O}_{2}$ and $\mathrm{H}_{2}$ can expand the bronchioles and reduce the inspiratory effort, and thus promote the absorption of $\mathrm{O}_{2}$ by the alveoli (Zhou et al., 2019). SARS-CoV-2 induced activation of p53 apoptosis signaling pathway in lymphocytes may play an important role in the development of lymphopenia of patients (Xiong et al., 2020). $\mathrm{H}_{2}$ may exert antiapoptotic effects in peripheral blood lymphocytes, a benefit to COVID19 (Sim et al., 2020); moreover, $\mathrm{H}_{2}$ can also increase surfactant proteins to further prevent lung injury (Huang et al., 2010), which may be used for prevention and treatment in patients with COVID-19. As a landmark event, recent public reports by China's National Health Commission and the Chinese Center for Disease Control and Prevention, the Chinese Clinical Guidance for COVID-19 Pneumonia Diagnosis and Treatment (7th edition) issued by China National Health Commission recommended the inhalation of $\mathrm{O}_{2}$ mixed with $\mathrm{H}_{2}$ gas $\left(33.3 \% \mathrm{O}_{2}\right.$ and $66.6 \%$ $\mathrm{H}_{2}$ ), bringing $\mathrm{H}_{2}$ to the forefront of contemporary therapeutic medical gas research.

Combined with the above researches, we hypothesize that $\mathrm{H}_{2}$ inhalation may be a promising approach to alleviate COVID19 by inhibiting oxidative stress, inflammation, and apoptosis to some extent, as shown in Figure 2.

\section{Effects on the Immune System}

In many inflammatory diseases, inflammation is mainly caused by the overactivation of cells and proinflammatory substances of the immune system. EAE is the classic animal model for human multiple sclerosis. $\mathrm{H}_{2}$-rich water intervention could alleviate EAE symptoms through reducing $\mathrm{CD} 4+\mathrm{T}$ cell infiltration and inhibiting Th17 cell differentiation in the spinal (Zhao et al., 2016). For immune deficiency, different concentrations of $\mathrm{H}_{2}$ can improve the immunodeficiency state and antitumor immune function by increasing the proportion of CD8+ T cells (Akagi 
and Baba, 2019). Radiation-induced immune dysfunction is the common adverse reaction in many patients subjected to radiotherapy. Studies have shown that pretreatment with $\mathrm{H}_{2}$ improved $\mathrm{CD} 4+$ and $\mathrm{CD} 8+\mathrm{T}$ cells and inhibited radiationinduced splenocytes apoptosis, which was against immune dysfunction in mice (Zhao et al., 2014). Moreover, after fourweek consumption of $\mathrm{H}_{2}$-water, inflammation and apoptosis signaling were significantly downregulated in peripheral blood lymphocytes of healthy adults (Sim et al., 2020). Allergic rhinitis is tissue congestion and edema caused by type I hypersensitivity reaction involved in mast cells and eosinophils activation. It can be relieved with a concentration of $67 \% \mathrm{H}_{2}$ through inhibiting the inflammatory response of Th2 cells (Huang et al., 2019). In addition, Xu et al. (2018) also demonstrated that $\mathrm{H}_{2}$-rich saline ameliorates allergic rhinitis by reversing the imbalance of Th1/Th2. Macrophage polarization and M1/M2 imbalance are pathological features of many inflammatory diseases (Shapouri-Moghaddam et al., 2018). Previous studies have reported that high concentration of $\mathrm{H}_{2}$ can improve the IL-4, an anti-inflammatory cytokine, by regulating the M1/M2 balance, and it exhibits significant effectiveness in acute kidney injury (Yao W. et al., 2019), rheumatoid arthritis (Meng J. et al., 2016), and ischemic stroke (Ning et al., 2018). $\mathrm{H}_{2}$ was first reported to restore Treg loss in a rat model of chronic pancreatitis, indicating $\mathrm{H}_{2}$ also regulates inflammation by mediating Treg. Low dose $\mathrm{H}_{2}$ intervention reduced inflammation by promoting Treg proliferation and inhibiting immune overactivation (Chen L. et al., 2017; Xu et al., 2018). Therefore, the different doses of $\mathrm{H}_{2}$ may balance immune overactivation or immunodeficiency by regulating immune cells proliferation, as shown in Figure 3.

\section{CONCLUSIONS}

Molecular hydrogen seems to exhibit a variety of phenotypes toward improving many pathogenic states by regulating various

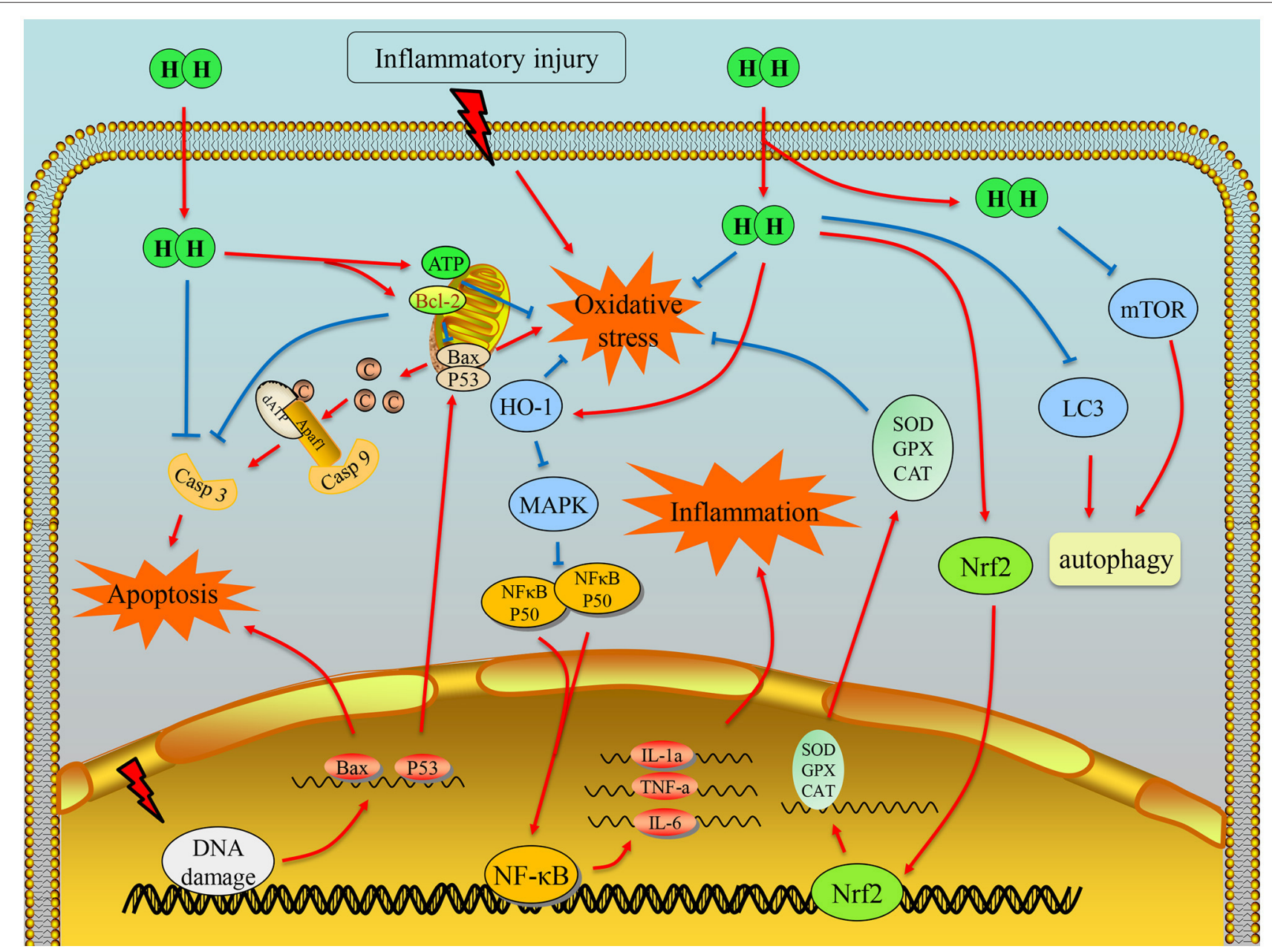

FIGURE 4 | Illustration of the main mechanism of hydrogen therapy in inflammatory diseases. First, hydrogen can scavenge hydroxyl radical due to its chemical property. It can also exert the antioxidation effects by regulating transcription of Nrf2 and energy balance of mitochondria. Moreover, hydrogen could downregulate the transcription of NF-kB, so that the inflammation can be alleviated. With the effects on antioxidation, anti-inflammation, and antiapoptosis factor Bcl-2 or direct interaction with caspase-3, hydrogen can inhibit cell apoptosis. 
gene expression. Many studies have shown that $\mathrm{H}_{2}$ intervention regulates inflammatory cytokines, scavenges free radicals, and alleviates cell apoptosis injury in vivo or in vitro, indicating a therapeutic effect of $\mathrm{H}_{2}$ on various acute or chronic inflammatory diseases.

In conclusion, we consider that $\mathrm{H}_{2}$ spreads into cells and regulates the potential imbalance of damaged mitochondrial membrane through electron transfer to reduce the generation of mitochondrial free radicals. It is also involved in the transcriptional regulation of $\mathrm{Nrf} 2$ and the occurrence of oxidative stress. For another aspect, $\mathrm{H}_{2}$ may inhibit the transcription of inflammation regulatory proteins, NF- $\kappa \mathrm{B}$ and Foxp3, in the nucleus, which can further affect the assembly of apoptotic proteins Bax and the phosphorylation of Caspase3 , and eventually prevent the initiation of apoptosis (Figure 4). Moreover, $\mathrm{H}_{2}$ acts as a potent antioxidant, and combined with the studies of respiratory system disease, we hypothesize that $\mathrm{H}_{2}$ inhalation may provide a meaningful approach to alleviate COVID-19 to some extent.

At present, studies of the prevention and treatment effects of $\mathrm{H}_{2}$ on many diseases are still at preliminary stage. Due to this critical difference in the experimental strategy between

\section{REFERENCES}

Akagi, J., and Baba, H. (2019). Hydrogen gas restores exhausted CD8+ T cells in patients with advanced colorectal cancer to improve prognosis. Oncol Rep 41, 301-311. doi: 10.3892/or.2018.6841

Akagi, J., and Baba, H. (2020). Hydrogen gas activates coenzyme Q10 to restore exhausted CD8(+) $\mathrm{T}$ cells, especially PD-1(+)Tim3(+)terminal CD8(+) T cells, leading to better nivolumab outcomes in patients with lung cancer. Oncol. Lett. 20:258. doi: 10.3892/ol.2020.12121

Alharbi, A. A. D., Ebine, N., Nakae, S., Hojo, T., and Fukuoka, Y. (2021). Application of molecular hydrogen as an antioxidant in responses to ventilatory and ergogenic adjustments during incremental exercise in humans. Nutrients 13:459. doi: 10.3390/nu13020459

Alwazeer, D., Liu, F. F., Wu, X. Y., and LeBaron, T. W. (2021). Combating oxidative stress and inflammation in COVID-19 by molecular hydrogen therapy: mechanisms and perspectives. Oxid. Med. Cell Longev. 2021:5513868. doi: $10.1155 / 2021 / 5513868$

Annesley, S. J., and Fisher, P. R. (2019). Mitochondria in health and disease. Cells 8:680. doi: $10.3390 /$ cells 8070680

Asada, R., Saitoh, Y., and Miwa, N. (2019). Effects of hydrogen-rich water bath on visceral fat and skin blotch, with boiling-resistant hydrogen bubbles. Med. Gas Res. 9, 68-73. doi: 10.4103/2045-9912.260647

Burton, G. J., and Jauniaux, E. (2011). Oxidative stress. Best Pract. Res. Clin. Obstet. Gynaecol. 25, 287-299. doi: 10.1016/j.bpobgyn.2010.10.016

Cascella, M., Rajnik, M., Aleem, A., Dulebohn, S. C., and Di Napoli, R. (2021). Features, Evaluation, and Treatment of Coronavirus (COVID-19). Treasure Island, FL: StatPearls Publishing.

Chen, H., Xie, K., Han, H., Li, Y., Liu, L., Yang, T., et al. (2015). Molecular hydrogen protects mice against polymicrobial sepsis by ameliorating endothelial dysfunction via an $\mathrm{Nrf} 2 / \mathrm{HO}-1$ signaling pathway. Int. Immunopharmacol. 28, 643-654. doi: 10.1016/j.intimp.2015.07.034

Chen, J. B., Kong, X. F., Qian, W., Mu, F., Lu, T. Y., and Lu, Y. Y. (2020). Two weeks of hydrogen inhalation can significantly reverse adaptive and innate immune system senescence patients with advanced non-small cell lung cancer: a selfcontrolled study. Med. Gas Res. 10, 149-154. doi: 10.4103/2045-9912.304221

Chen, L., Ma, C., Bian, Y., Li, J., Wang, T., Su, L., et al. (2017). hydrogen treatment protects mice against chronic pancreatitis by restoring regulatory $\mathrm{T}$ cells loss. Cell. Physiol. Biochem. 44, 2005-2016. doi: 10.1159/000485906 efficacy testing in animals/cultured cells and clinical trials, further research is needed. It appears that not all studies showed corroborative effects. In order to achieve better results in clinical trials, it is proposed that knowledge involving the effects of excess accumulation, reducing potential, the dosage, the dose duration, and the safety of the antioxidant should all be determined. However, all the findings suggest that $\mathrm{H}_{2}$ is a novel and a promising antioxidant agent, and despite its efficacy it has to be further validated and characterized in clinical and animal trials.

\section{AUTHOR CONTRIBUTIONS}

YW, JQ, and JZ designed and outlined the work. YT, YZ, YW, YC, and WF drafted and revised the manuscript. All authors approved the final version of the article and agreed to be accountable for all aspects of the work.

\section{FUNDING}

This work was supported by Small and Micro Science and Technology Project grant (No. 20004 to YW) from the National Health Commission.

Chen, M., Zhang, J., Chen, Y., Qiu, Y., Luo, Z., Zhao, S., et al. (2018). Hydrogen protects lung from hypoxia/re-oxygenation injury by reducing hydroxyl radical production and inhibiting inflammatory responses. Sci. Rep. 8:8004. doi: 10.1038/s41598-018-26335-2

Chen, O., Cao, Z., Li, H., Ye, Z., Zhang, R., Zhang, N., et al. (2017). Highconcentration hydrogen protects mouse heart against ischemia/reperfusion injury through activation of thePI3K/Akt1 pathway. Sci. Rep. 7:14871. doi: 10.1038/s41598-017-14072-x

Cole, A. R., Sperotto, F., DiNardo, J. A., Carlisle, S., Rivkin, M. J., Sleeper, L. A., et al. (2021). Safety of prolonged inhalation of hydrogen gas in air in healthy adults. Crit. Care Explor. 3:e543. doi: 10.1097/CCE.0000000000000543

Dan Dunn, J., Alvarez, L. A., Zhang, X., and Soldati, T. (2015). Reactive oxygen species and mitochondria: a nexus of cellular homeostasis. Redox Biol. 6, 472-485. doi: 10.1016/j.redox.2015.09.005

Deng, M., Tang, Y., Li, W., Wang, X., Zhang, R., Zhang, X., et al. (2018). The endotoxin delivery protein HMGB1 mediates caspase-11-dependent lethality in sepsis. Immunity 49, 740-753.e7. doi: 10.1016/j.immuni.2018.08.016

DiPasquale, M., Gbadamosi, O., Nguyen, M. H. L., Castillo, S. R., Rickeard, B. W., Kelley, E. G., et al. (2020). A mechanical mechanism for vitamin E acetate in E-cigarette/vaping-associated lung injury. Chem. Res. Toxicol. 33, 2432-2440. doi: 10.1021/acs.chemrestox.0c00212

Dixon, B. J., Tang, J., and Zhang, J. H. (2013). The evolution of molecular hydrogen: a noteworthy potential therapy with clinical significance. Med. Gas Res. 3:10. doi: 10.1186/2045-9912-3-10

Dole, M., Wilson, F. R., and Fife, W. P. (1975). Hyperbaric hydrogen therapy: a possible treatment for cancer. Science 190, 152-154. doi: 10.1126/science.1166304

Dukhinova, M., Kokinos, E., Kuchur, P., Komissarov, A., and Shtro, A. (2021). Macrophage-derived cytokines in pneumonia: linking cellular immunology and genetics. Cytokine Growth Factor Rev. 59, 46-61. doi: 10.1016/j.cytogfr.2020.11.003

Eming, S. A., Wynn, T. A., and Martin, P. (2017). Inflammation and metabolism in tissue repair and regeneration. Science 356, 1026-1030. doi: 10.1126/science.aam7928

Feng, S., Duan, E., Shi, X., Zhang, H., Li, H., Zhao, Y., et al. (2019). Hydrogen ameliorates lung injury in a rat model of subacute exposure to concentrated ambient PM2.5 via Aryl hydrocarbon receptor. Int. Immunopharmacol. 77:105939. doi: 10.1016/j.intimp.2019.105939 
Forrester, S. J., Kikuchi, D. S., Hernandes, M. S., Xu, Q., and Griendling, K. K. (2018). Reactive oxygen species in metabolic and inflammatory signaling. Circ. Res. 122, 877-902. doi: 10.1161/CIRCRESAHA.117.311401

Fujioka, K., Kalish, F., Zhao, H., Lu, S., Wong, S., Wong, R. J., et al. (2017). Induction of heme oxygenase-1 attenuates the severity of sepsis in a non-surgical preterm mouse model. Shock 47, 242-250. doi: 10.1097/SHK.0000000000000689

Fukuda, K., Asoh, S., Ishikawa, M., Yamamoto, Y., Ohsawa, I., and Ohta, S. (2007). Inhalation of hydrogen gas suppresses hepatic injury caused by ischemia/reperfusion through reducing oxidative stress. Biochem. Biophys. Res. Commun. 361, 670-674. doi: 10.1016/j.bbrc.2007.07.088

Gharib, B., Hanna, S., Abdallahi, O. M., Lepidi, H., Gardette, B., and De Reggi, M. (2001). Anti-inflammatory properties of molecular hydrogen: investigation on parasite-induced liver inflammation. C. R. Acad. Sci. III 324, 719-724. doi: 10.1016/S0764-4469(01)01350-6

Guan, P., Sun, Z. M., Luo, L. F., Zhou, J., Yang, S., Zhao, Y. S., et al. (2019). Hydrogen protects against chronic intermittent hypoxia induced renal dysfunction by promoting autophagy and alleviating apoptosis. Life Sci. 225, 46-54. doi: 10.1016/j.lfs.2019.04.005

Guan, W. J., Chen, R. C., and Zhong, N. S. (2020a). Strategies for the prevention and management of coronavirus disease 2019. Eur. Respir. J. 55:2000597. doi: 10.1183/13993003.00597-2020

Guan, W. J., Wei, C. H., Chen, A. L., Sun, X. C., Guo, G. Y., Zou, X., et al. (2020b). Hydrogen/oxygen mixed gas inhalation improves disease severity and dyspnea in patients with Coronavirus disease 2019 in a recent multicenter, open-label clinical trial. J. Thorac. Dis. 12, 3448-3452. doi: 10.21037/jtd-2020-057

Gutierrez-Mariscal, F. M., Arenas-de Larriva, A. P., Limia-Perez, L., RomeroCabrera, J. L., Yubero-Serrano, E. M., and Lopez-Miranda, J. (2020). Coenzyme Q10 supplementation for the reduction of oxidative stress: clinical implications in the treatment of chronic diseases. Int. J. Mol. Sci. 21:7870. doi: $10.3390 /$ ijms 21217870

Gvozdjakova, A., Kucharska, J., Kura, B., Vancova, O., Rausova, Z., and Sumbalova, Z. (2020). A new insight into the molecular hydrogen effect on coenzyme $\mathrm{Q}$ and mitochondrial function of rats. Can. J. Physiol. Pharmacol. 98, 29-34. doi: 10.1139/cjpp-2019-0281

Han, H., Ma, Q., Li, C., Liu, R., Zhao, L., Wang, W., et al. (2020). Profiling serum cytokines in COVID-19 patients reveals IL-6 and IL10 are disease severity predictors. Emerg. Microbes Infect. 9, 1123-1130. doi: 10.1080/22221751.2020.1770129

He, Y., Zhang, B., Chen, Y., Jin, Q., Wu, J., and Yan, F. (2017). Image-guided hydrogen gas delivery for protection from myocardial ischemia-reperfusion injury via microbubbles. ACS Appl. Mater. Interfaces 9, 21190-21199. doi: 10.1021/acsami.7b05346

Hirayama, M., Ito, M., Minato, T., Yoritaka, A., LeBaron, T. W., and Ohno, K. (2018). Inhalation of hydrogen gas elevates urinary 8-hydroxy2'-deoxyguanine in Parkinson's disease. Med. Gas Res. 8, 144-149. doi: 10.4103/2045-9912.248264

Huang, C. S., Kawamura, T., Lee, S., Tochigi, N., Shigemura, N., Buchholz, B. M., et al. (2010). Hydrogen inhalation ameliorates ventilator-induced lung injury. Crit. Care 14:R234. doi: 10.1186/cc9389

Huang, L. (2016). Molecular hydrogen: a therapeutic antioxidant and beyond. Med. Gas Res. 6, 219-222. doi: 10.4103/2045-9912.196904

Huang, P., Wei, S., Huang, W., Wu, P., Chen, S., Tao, A., et al. (2019). Hydrogen gas inhalation enhances alveolar macrophage phagocytosis in an ovalbumin-induced asthma model. Int. Immunopharmacol. 74:105646. doi: 10.1016/j.intimp.2019.05.031

Hylemon, P. B., Harris, S. C., and Ridlon, J. M. (2018). Metabolism of hydrogen gases and bile acids in the gut microbiome. FEBS Lett. 592, 2070-2082. doi: 10.1002/1873-3468.13064

Ito, M., Hirayama, M., Yamai, K., Goto, S., and Ichihara, M. (2012). Drinking hydrogen water and intermittent hydrogen gas exposure, but not lactulose or continuous hydrogen gas exposure, prevent 6-hydorxydopamine-induced Parkinson's disease in rats. Med. Gas Res. 2:15. doi: 10.1186/2045-9912-2-15

Iuchi, K., Nishimaki, K., Kamimura, N., and Ohta, S. (2019). Molecular hydrogen suppresses free-radical-induced cell death by mitigating fatty acid peroxidation and mitochondrial dysfunction. Can. J. Physiol. Pharmacol. 97, 999-1005. doi: 10.1139/cjpp-2018-0741
Kiyoi, T., Liu, S., Takemasa, E., Nakaoka, H., Hato, N., and Mogi, M. (2020). Constitutive hydrogen inhalation prevents vascular remodeling via reduction of oxidative stress. PLoS ONE 15:e0227582. doi: 10.1371/journal.pone.0227582

Kurokawa, R., Hirano, S. I., Ichikawa, Y., Matsuo, G., and Takefuji, Y. (2019). Preventing explosions of hydrogen gas inhalers. Med. Gas Res. 9, 160-162. doi: $10.4103 / 2045-9912.266996$

Lanphier, E. H. (1972). Human respiration under increased pressures. Symp. Soc. Exp. Biol. 26, 379-394.

LeBaron, T. W., Kura, B., Kalocayova, B., Tribulova, N., and Slezak, J. (2019). A new approach for the prevention and treatment of cardiovascular disorders. Molecular hydrogen significantly reduces the effects of oxidative stress. Molecules 24:2076. doi: 10.3390/molecules24112076

Li, H., Chen, O., Ye, Z., Zhang, R., Hu, H., Zhang, N., et al. (2017). Inhalation of high concentrations of hydrogen ameliorates liver ischemia/reperfusion injury through A2A receptor mediated PI3K-Akt pathway. Biochem. Pharmacol. 130, 83-92. doi: 10.1016/j.bcp.2017.02.003

Li, Q., Tanaka, Y., and Miwa, N. (2017). Influence of hydrogen-occluding-silica on migration and apoptosis in human esophageal cells in vitro. Med. Gas Res. 7, 76-85. doi: 10.4103/2045-9912.208510

Li, Q., Yu, P., Zeng, Q., Luo, B., Cai, S., Hui, K., et al. (2016). Neuroprotective effect of hydrogen-rich saline in global cerebral ischemia/reperfusion rats: up-regulated tregs and down-regulated miR-21, miR-210 and NF-kappaB expression. Neurochem. Res. 41, 2655-2665. doi: 10.1007/s11064-016-1978-x

Liu, C., Kurokawa, R., Fujino, M., Hirano, S., Sato, B., and Li, X. K. (2014). Estimation of the hydrogen concentration in rat tissue using an airtight tube following the administration of hydrogen via various routes. Sci. Rep. 4:5485. doi: 10.1038/srep05485

Liu, L., Yan, Z., Wang, Y., Meng, J., and Chen, G. (2020). Suppression of autophagy facilitates hydrogen gas-mediated lung cancer cell apoptosis. Oncol. Lett. 20:112. doi: 10.3892/ol.2020.11973

Liu, Q., Li, B. S., Song, Y. J., Hu, M. G., Lu, J. Y., Gao, A., et al. (2016). Hydrogen-rich saline protects against mitochondrial dysfunction and apoptosis in mice with obstructive jaundice. Mol. Med. Rep. 13, 3588-3596. doi: $10.3892 / \mathrm{mmr} .2016 .4954$

Liu, X., Ma, C., Wang, X., Wang, W., Li, Z., Wang, X., et al. (2017). Hydrogen coadministration slows the development of COPD-like lung disease in a cigarette smoke-induced rat model. Int. J. Chron. Obstruct. Pulmon. Dis. 12, 1309-1324. doi: 10.2147/COPD.S124547

Liu, Y., Dong, F., Guo, R., Zhang, Y., Qu, X., and Wu, X. (2019). Hydrogen-rich saline ameliorates experimental autoimmune encephalomyelitis in C57BL/6 mice via the Nrf2-ARE signaling pathway. Inflammation 42, 586-597. doi: 10.1007/s10753-018-0915-3

Man, S. M., Karki, R., and Kanneganti, T. D. (2017). Molecular mechanisms and functions of pyroptosis, inflammatory caspases and inflammasomes in infectious diseases. Immunol. Rev. 277, 61-75. doi: 10.1111/imr.12534

Meng, C., Ma, L., Niu, L., Cui, X., Liu, J., Kang, J., et al. (2016). Protection of donor lung inflation in the setting of cold ischemia against ischemia-reperfusion injury with carbon monoxide, hydrogen, or both in rats. Life Sci. 151, 199-206. doi: 10.1016/j.lfs.2016.03.015

Meng, J., Liu, L., Wang, D., Yan, Z., and Chen, G. (2020). Hydrogen gas represses the progression of lung cancer via down-regulating CD47. Biosci. Rep. 40:BSR20192761. doi: 10.1042/BSR20192761

Meng, J., Yu, P., Jiang, H., Yuan, T., Liu, N., Tong, J., et al. (2016). Molecular hydrogen decelerates rheumatoid arthritis progression through inhibition of oxidative stress. Am. J. Transl. Res. 8, 4472-447.

Mittal, M., Siddiqui, M. R., Tran, K., Reddy, S. P., and Malik, A. B. (2014). Reactive oxygen species in inflammation and tissue injury. Antioxid. Redox Signal 20, 1126-1167. doi: 10.1089/ars.2012.5149

Mo, X. Y., Li, X. M., She, C. S., Lu, X. Q., Xiao, C. G., Wang, S. H., et al. (2019). Hydrogen-rich saline protects rat from oxygen glucose deprivation and reperusion-induced apoptosis through VDAC1 via Bcl-2. Brain Res. 1706, 110-115. doi: 10.1016/j.brainres.2018.09.037

Ning, K., Liu, W. W., Huang, J. L., Lu, H. T., and Sun, X. J. (2018). Effects of hydrogen on polarization of macrophages and microglia in a stroke model. Med. Gas Res. 8, 154-159. doi: 10.4103/2045-9912.248266

Ning, Y., Shang, Y., Huang, H., Zhang, J., Dong, Y., Xu, W., et al. (2013). Attenuation of cigarette smoke-induced airway mucus 
production by hydrogen-rich saline in rats. PLoS ONE 8:e83429. doi: 10.1371/journal.pone.0083429

Noda, K., Shigemura, N., Tanaka, Y., Kawamura, T., Hyun Lim, S., and Kokubo, K. (2013). A novel method of preserving cardiac grafts using a hydrogen-rich water bath. J. Heart Lung Transplant. 32, 241-250. doi: 10.1016/j.healun.2012.11.004

Nogueira, J. E., Amorim, M. R., Pinto, A. P., da Rocha, A. L., da Silva, A. S. R., and Branco, L. G. S. (2020). Molecular hydrogen downregulates acute exhaustive exercise-induced skeletal muscle damage. Can. J. Physiol. Pharmacol. 99, 812-820 doi: 10.1139/cjpp-2020-0297

Obeng, E. (2021). Apoptosis (programmed cell death) and its signals - a review. Braz. J. Biol. 81, 1133-1143. doi: 10.1590/1519-6984.228437

Oharazawa, H., Igarashi, T., Yokota, T., Fujii, H., Suzuki, H., and Machide, M. (2010). Protection of the retina by rapid diffusion of hydrogen: administration of hydrogen-loaded eye drops in retinal ischemia-reperfusion injury. Invest. Ophthalmol. Vis. Sci. 51, 487-492. doi: 10.1167/iovs.09-4089

Ohsawa, I., Ishikawa, M., Takahashi, K., Watanabe, M., Nishimaki, K., and Yamagata, K. (2007). Hydrogen acts as a therapeutic antioxidant by selectively reducing cytotoxic oxygen radicals. Nat. Med. 13, 688-694. doi: $10.1038 / \mathrm{nm} 1577$

Ohta, S. (2014). Molecular hydrogen as a preventive and therapeutic medical gas: initiation, development and potential of hydrogen medicine. Pharmacol. Ther. 144, 1-11. doi: 10.1016/j.pharmthera.2014.04.006

Ostojic, S. M. (2015). Targeting molecular hydrogen to mitochondria: barriers and gateways. Pharmacol. Res. 94, 51-53. doi: 10.1016/j.phrs.2015.02.004

Ostojic, S. M., Vukomanovic, B., Calleja-Gonzalez, J., and Hoffman, J. R. (2014). Effectiveness of oral and topical hydrogen for sports-related soft tissue injuries. Postgrad. Med. 126, 187-195. doi: 10.3810/pgm.2014.09.2813

Poljsak, B., Suput, D., and Milisav, I. (2013). Achieving the balance between ROS and antioxidants: when to use the synthetic antioxidants. Oxid. Med. Cell Longev. 2013:956792. doi: 10.1155/2013/956792

Qian, L., Liu, J., Ma, W., Liu, Y., Wang, X., and Liu, D. (2021). Hydrogen-rich water ameliorates murine chronic graft-versus-host disease through antioxidation. Oxid. Med. Cell Longev. 2021:1165928. doi: 10.1155/2021/1165928

Qiu, P., Liu, Y., and Zhang, J. (2019). Recent advances in studies of molecular hydrogen against sepsis. Int. J. Biol. Sci. 15, 1261-1275. doi: 10.7150/ijbs.30741

Qiu, X., Dong, K., Guan, J., and He, J. (2020). Hydrogen attenuates radiation-induced intestinal damage by reducing oxidative stress and inflammatory response. Int. Immunopharmacol. 84:106517. doi: 10.1016/j.intimp.2020.106517

Rimessi, A., Previati, M., Nigro, F., Wieckowski, M. R., and Pinton, P. (2016). Mitochondrial reactive oxygen species and inflammation: molecular mechanisms, diseases and promising therapies. Int. J. Biochem. Cell Biol. 81(Pt B), 281-293. doi: 10.1016/j.biocel.2016.06.015

Rossi, I., Sonvico, F., McConville, J. T., Rossi, F., Frohlich, E., Zellnitz, S., et al. (2018). Nebulized coenzyme Q10 nanosuspensions: a versatile approach for pulmonary antioxidant therapy. Eur. J. Pharm. Sci. 113, 159-170. doi: 10.1016/j.ejps.2017.10.024

Sano, M., Ichihara, G., Katsumata, Y., Hiraide, T., Hirai, A., and Momoi, M. (2020), Pharmacokinetics of a single inhalation of hydrogen gas in pigs. PLoS ONE 15:e0234626. doi: 10.1371/journal.pone.0234626

Shao, A., Wu, H., Hong, Y., Tu, S., Sun, X., Wu, Q., et al. (2016). Hydrogenrich saline attenuated subarachnoid hemorrhage-induced early brain injury in rats by suppressing inflammatory response: possible involvement of NFkappaB pathway and NLRP3 inflammasome. Mol. Neurobiol. 53, 3462-3476. doi: $10.1007 /$ s12035-015-9242-y

Shapouri-Moghaddam, A., Mohammadian, S., Vazini, H., Taghadosi, M., Esmaeili, S. A., Mardani, F., et al. (2018). Macrophage plasticity, polarization, and function in health and disease. J. Cell Physiol. 233, 6425-6440. doi: $10.1002 /$ jcp. 26429

Shimouchi, A., Nose, K., Shirai, M., and Kondo, T. (2012). Estimation of molecular hydrogen consumption in the human whole body after the ingestion of hydrogen-rich water. Adv. Exp. Med. Biol. 737, 245-250. doi: 10.1007/978-1-4614-1566-4_36

Shin, W. (2014). Medical applications of breath hydrogen measurements. Anal. Bioanal. Chem. 406, 3931-3939. doi: 10.1007/s00216-013-7606-6

Sim, M., Kim, C. S., Shon, W. J., Lee, Y. K., Choi, E. Y., and Shin, D. M. (2020). Hydrogen-rich water reduces inflammatory responses and prevents apoptosis of peripheral blood cells in healthy adults: a randomized, doubleblind, controlled trial. Sci. Rep. 10:12130. doi: 10.1038/s41598-020-68930-2

Singh, K., Bhori, M., Kasu, Y. A., Bhat, G., and Marar, T. (2018). Antioxidants as precision weapons in war against cancer chemotherapy induced toxicity - exploring the armoury of obscurity. Saudi Pharm. J. 26, 177-190. doi: $10.1016 /$ j.jsps.2017.12.013

Sobue, S., Yamai, K., Ito, M., Ohno, K., and Iwamoto, T. (2015). Simultaneous oral and inhalational intake of molecular hydrogen additively suppresses signaling pathways in rodents. Mol. Cell Biochem. 403, 231-241. doi: 10.1007/s11010-015-2353-y

Su, N., Wu, Q., Chen, H., Huang, Y., Zhu, Z., and Chen, Y. (2019). Hydrogen gas alleviates toxic effects of cadmium in Brassica campestris seedlings through upregulation of the antioxidant capacities: possible involvement of nitric oxide. Environ. Pollut. 251, 45-55. doi: 10.1016/j.envpol.2019.03.094

Tamura, T., Suzuki, M., Hayashida, K., Kobayashi, Y., Yoshizawa, J., and Shibusawa, T. (2020). Hydrogen gas inhalation alleviates oxidative stress in patients with post-cardiac arrest syndrome. J. Clin. Biochem. Nutr. 67, 214-221. doi: $10.3164 /$ jcbn.19-101

Tan, Y. C., Xie, F., Zhang, H. L., Zhu, Y. L., Chen, K., Tan, H. M., et al. (2014). Hydrogen-rich saline attenuates postoperative liver failure after major hepatectomy in rats. Clin. Res. Hepatol. Gastroenterol. 38, 337-345. doi: 10.1016/j.clinre.2013.11.007

Terasaki, Y., Ohsawa, I., Terasaki, M., Takahashi, M., Kunugi, S., Dedong, K., et al. (2011). Hydrogen therapy attenuates irradiation-induced lung damage by reducing oxidative stress. Am. J. Physiol. Lung Cell Mol. Physiol. 301, L415-L426. doi: 10.1152/ajplung.00008.2011

Tonelli, C., Chio, I. I. C., and Tuveson, D. A. (2018). Transcriptional regulation by Nrf2. Antioxid. Redox Signal 29, 1727-1745. doi: 10.1089/ars.2017.7342

Wang, C., Li, J., Liu, Q., Yang, R., Zhang, J. H., Cao, Y. P., et al. (2011). Hydrogenrich saline reduces oxidative stress and inflammation by inhibit of JNK and NFkappaB activation in a rat model of amyloid-beta-induced Alzheimer's disease. Neurosci. Lett. 491, 127-132. doi: 10.1016/j.neulet.2011.01.022

Wang, J., Hossain, M., Thanabalasuriar, A., Gunzer, M., Meininger, C., and Kubes, P. (2017). Visualizing the function and fate of neutrophils in sterile injury and repair. Science 358, 111-116. doi: 10.1126/science.aam9690

Wang, P., Zhao, M., Chen, Z., Wu, G., Fujino, M., Zhang, C., et al. (2020). Hydrogen gas attenuates hypoxic-ischemic brain injury via regulation of the MAPK/HO-1/PGC-1a pathway in neonatal rats. Oxid. Med. Cell Longev. 2020:6978784. doi: 10.1155/2020/6978784

Wang, S. T., Bao, C., He, Y., Tian, X., Yang, Y., and Zhang, T. (2020). Hydrogen gas (XEN) inhalation ameliorates airway inflammation in asthma and COPD patients. QJM 113, 870-875. doi: 10.1093/qjmed/hcaa164

Wang, X., Yu, P., YongYang Liu, X., Jiang, J., Liu, D., et al. (2015). Hydrogenrich saline resuscitation alleviates inflammation induced by severe burn with delayed resuscitation. Burns 41, 379-385. doi: 10.1016/j.burns.2014.07.012

Wu, D., Liang, M., Dang, H., Fang, F., Xu, F., and Liu, C. (2018). Hydrogen protects against hyperoxia-induced apoptosis in type II alveolar epithelial cells via activation of PI3K/Akt/Foxo3a signaling pathway. Biochem. Biophys. Res. Commun. 495, 1620-1627. doi: 10.1016/j.bbrc.2017.11.193

Wu, X., Li, X., Liu, Y., Yuan, N., Li, C., Kang, Z., et al. (2018). Hydrogen exerts neuroprotective effects on $\mathrm{OGD} / \mathrm{R}$ damaged neurons in rat hippocampal by protecting mitochondrial function via regulating mitophagy mediated by PINK1/Parkin signaling pathway. Brain Res. 1698, 89-98. doi: 10.1016/j.brainres.2018.06.028

Xie, K., Wang, Y., Yin, L., Wang, Y., Chen, H., Mao, X., et al. (2021). Hydrogen gas alleviates sepsis-induced brain injury by improving mitochondrial biogenesis through the activation of PGC-alpha in mice. Shock 55, 100-109. doi: 10.1097/SHK.0000000000001594

Xie, K., Zhang, Y., Wang, Y., Meng, X., Wang, Y., Yu, Y., et al. (2020). Hydrogen attenuates sepsis-associated encephalopathy by NRF2 mediated NLRP3 pathway inactivation. Inflamm. Res. 69, 697-710. doi: 10.1007/s00011-020-01347-9

Xiong, Y., Liu, Y., Cao, L., Wang, D., Guo, M., Jiang, A., et al. (2020). Transcriptomic characteristics of bronchoalveolar lavage fluid and peripheral blood mononuclear cells in COVID-19 patients. Emerg. Microbes Infect. 9, 761-770. doi: 10.1080/22221751.2020.1747363

Xu, F., Yu, S., Qin, M., Mao, Y., Jin, L., Che, N., et al. (2018). Hydrogen-rich saline ameliorates allergic rhinitis by reversing the imbalance of Th1/Th2 
and up-regulation of CD4+CD25+Foxp3+regulatory T cells, interleukin10 , and membrane-bound transforming growth factor-beta in guinea pigs. Inflammation 41, 81-92. doi: 10.1007/s10753-017-0666-6

Xu, Z., Shi, L., Wang, Y., Zhang, J., Huang, L., Zhang, C., et al. (2020). Pathological findings of COVID-19 associated with acute respiratory distress syndrome. Lancet Respir. Med. 8, 420-422. doi: 10.1016/S2213-2600(20)30076-X

Yan, M., Yu, Y., Mao, X., Feng, J., Wang, Y., Chen, H., et al. (2019). Hydrogen gas inhalation attenuates sepsis-induced liver injury in a FUNDC1-dependent manner. Int. Immunopharmacol. 71, 61-67. doi: 10.1016/j.intimp.2019.03.021

Yang, Y., Liu, P. Y., Bao, W., Chen, S. J., Wu, F. S., and Zhu, P. Y. (2020). Hydrogen inhibits endometrial cancer growth via a ROS/NLRP3/caspase-1/GSDMD-mediated pyroptotic pathway. BMC Cancer 20:28. doi: 10.1186/s12885-019-6491-6

Yao, L., Chen, H., Wu, Q., and Xie, K. (2019). Hydrogen-rich saline alleviates inflammation and apoptosis in myocardial I/R injury via PINK-mediated autophagy. Int. J. Mol. Med. 44, 1048-1062. doi: 10.3892/ijmm.2019.4264

Yao, W., Guo, A., Han, X., Wu, S., Chen, C., Luo, C., et al. (2019). Aerosol inhalation of a hydrogen-rich solution restored septic renal function. Aging (Albany NY) 11, 12097-12113. doi: 10.18632/aging.102542

Yin, L., i,. K., Duan, H., Lai, Y., Cai, P., and Wei, Y. (2021). Pre-inhalation of hydrogen-rich gases protect against caerulein-induced mouse acute pancreatitis while enhance the pancreatic Hsp60 protein expression. $B M C$ Gastroenterol. 21:178. doi: 10.1186/s12876-021-01640-9

Yoritaka, A., Kobayashi, Y., Hayashi, T., Saiki, S., and Hattori, N. (2021). Randomized double-blind placebo-controlled trial of hydrogen inhalation for Parkinson's disease: a pilot study. Neurol. Sci. 42:4767-4770 doi: 10.1007/s10072-021-05489-4

Yoshida, A., Asanuma, H., Sasaki, H., Sanada, S., Yamazaki, S., and Asano, Y. (2012). H(2) mediates cardioprotection via involvements of K(ATP) channels and permeability transition pores of mitochondria in dogs. Cardiovasc. Drugs Ther. 26, 217-226. doi: 10.1007/s10557-012-6381-5

Yu, Y., Yang, Y., Yang, M., Wang, C., Xie, K., and Yu, Y. (2019). Hydrogen gas reduces HMGB1 release in lung tissues of septic mice in an Nrf2/HO-1-dependent pathway. Int. Immunopharmacol. 69, 11-18. doi: 10.1016/j.intimp.2019.01.022

Zhai, Y., Zhou, X., Dai, Q., Fan, Y., and Huang, X. (2015). Hydrogen-rich saline ameliorates lung injury associated with cecal ligation and puncture-induced sepsis in rats. Exp. Mol. Pathol. 98, 268-276. doi: 10.1016/j.yexmp.2015.03.005

Zhang, N., Deng, C., Zhang, X., Zhang, J., and Bai, C. (2018). Inhalation of hydrogen gas attenuates airway inflammation and oxidative stress in allergic asthmatic mice. Asthma Res. Pract. 4:3. doi: 10.1186/s40733-018$0040-y$

Zhang, Q., Ge, Y., Li, H., Bai, G., Jiao, Z., Kong, X., et al. (2018). Effect of hydrogen-rich saline on apoptosis induced by hepatic ischemia reperfusion upon laparoscopic hepatectomy in miniature pigs. Res. Vet. Sci. 119, 285-291. doi: 10.1016/j.rvsc.2018.07.005

Zhang, Y., Dong, A., Xie, K., and Yu, Y. (2020). Protective effects of hydrogen on myocardial mitochondrial functions in septic mice. Biomed. Res. Int. 2020:1568209.; publication of this article. doi: 10.1155/2020/1568209

Zhang, Y., Liu, Y., and Zhang, J. (2015). Saturated hydrogen saline attenuates endotoxin-induced lung dysfunction. J. Surg. Res. 198, 41-49. doi: 10.1016/j.jss.2015.04.055

Zhang, Y., Long, Z., Xu, J., Tan, S., Zhang, N., Li, A., et al. (2017). Hydrogen inhibits isoproterenolinduced autophagy in cardiomyocytes in vitro and in vivo. Mol. Med. Rep. 16, 8253-8258. doi: 10.3892/mmr.2017.7601

Zhao, M., Liu, M. D., Pu, Y. Y., Wang, D., Xie, Y., Xue, G. C., et al. (2016). Hydrogen-rich water improves neurological functional recovery in experimental autoimmune encephalomyelitis mice. J. Neuroimmunol. 294, 6-13. doi: 10.1016/j.jneuroim.2016.03.006
Zhao, S., Mei, K., Qian, L., Yang, Y., Liu, W., Huang, Y., et al. (2013). Therapeutic effects of hydrogen-rich solution on aplastic anemia in vivo. Cell Physiol. Biochem. 32, 549-560. doi: 10.1159/000354459

Zhao, S., Yang, Y., Liu, W., Xuan, Z., Wu, S., Yu, S., et al. (2014). Protective effect of hydrogen-rich saline against radiation-induced immune dysfunction. J. Cell Mol. Med. 18, 938-946. doi: 10.1111/jcmm.12245

Zhao, Y. S., An, J. R., Yang, S., Guan, P., Yu, F. Y., Li, W., et al. (2019). Hydrogen and oxygen mixture to improve cardiac dysfunction and myocardial pathological changes induced by intermittent hypoxia in rats. Oxid. Med. Cell Longev. 2019:7415212. doi: 10.1155/2019/7415212

Zheng, P., Kang, J., Xing, E., Zheng, B., Wang, X., and Zhou, H. (2021). Lung inflation with hydrogen during the cold ischemia phase alleviates lung ischemia-reperfusion injury by inhibiting pyroptosis in rats. Front. Physiol. 12:699344. doi: 10.3389/fphys.2021.699344

Zheng, Z. G., Sun, W. Z., Hu, J. Y., Jie, Z. J., Xu, J. F., and Cao, J. (2021). Hydrogen/oxygen therapy for the treatment of an acute exacerbation of chronic obstructive pulmonary disease: results of a multicenter, randomized, double-blind, parallel-group controlled trial. Respir. Res. 22:149. doi: 10.1186/s12931-021-01740-w

Zhou, H. X., Han, B., Hou, L. M., An, T. T., Jia, G., Cheng, Z. X., et al. (2016). Protective effects of hydrogen gas on experimental acute pancreatitis. PLoS ONE 11:e0154483. doi: 10.1371/journal.pone.0154483

Zhou, Z. Q., Zhong, C. H., Su, Z. Q., Li, X. Y., Chen, Y., and Chen, X. B. (2019). Breathing hydrogen-oxygen mixture decreases inspiratory effort in patients with tracheal stenosis. Respiration 97, 42-51. doi: 10.1159/000492031

Zhu, Q., Wu, Y., Li, Y., Chen, Z., Wang, L., Xiong, H., et al. (2018). Positive effects of hydrogen-water bathing in patients of psoriasis and parapsoriasis en plaques. Sci. Rep. 8:8051. doi: 10.1038/s41598-018-26388-3

Zhuang, K., Zuo, Y. C., Sherchan, P., Wang, J. K., Yan, X. X., and Liu, F. (2019). Hydrogen inhalation attenuates oxidative stress related endothelial cells injury after subarachnoid hemorrhage in rats. Front. Neurosci. 13:1441. doi: 10.3389/fnins.2019.01441

Zhuang, X., Yu, Y., Jiang, Y., Zhao, S., Wang, Y., Su, L., et al. (2020). Molecular hydrogen attenuates sepsis-induced neuroinflammation through regulation of microglia polarization through an mTOR-autophagy-dependent pathway. Int. Immunopharmacol. 81:106287. doi: 10.1016/j.intimp.2020.106287

Zou, R., Wang, M. H., Chen, Y., Fan, X., Yang, B., Du, J., et al. (2019). Hydrogenrich saline attenuates acute lung injury induced by limb ischemia/reperfusion via down-regulating chemerin and NLRP3 in rats. Shock 52, 134-141. doi: $10.1097 /$ SHK.0000000000001194

Conflict of Interest: The authors declare that the research was conducted in the absence of any commercial or financial relationships that could be construed as a potential conflict of interest.

Publisher's Note: All claims expressed in this article are solely those of the authors and do not necessarily represent those of their affiliated organizations, or those of the publisher, the editors and the reviewers. Any product that may be evaluated in this article, or claim that may be made by its manufacturer, is not guaranteed or endorsed by the publisher.

Copyright (๑) 2021 Tian, Zhang, Wang, Chen, Fan, Zhou, Qiao and Wei. This is an open-access article distributed under the terms of the Creative Commons Attribution License (CC BY). The use, distribution or reproduction in other forums is permitted, provided the original author(s) and the copyright owner(s) are credited and that the original publication in this journal is cited, in accordance with accepted academic practice. No use, distribution or reproduction is permitted which does not comply with these terms. 